\title{
Study of the Corrosion Process of AZ91D Magnesium Alloy during the First Hours of Immersion in 3.5 wt.\% NaCl Solution
}

\author{
Vanessa Mandarano Pinela, Leandro Antônio de Oliveira, \\ Mara Cristina Lopes de Oliveira $\mathbb{D}$, and Renato Altobelli Antunes $\mathbb{1}$ \\ Universidade Federal do ABC (UFABC), Centro de Engenharia, Modelagem e Ciências Sociais Aplicadas (CECS), \\ 09210-580 Santo André, SP, Brazil \\ Correspondence should be addressed to Renato Altobelli Antunes; renato.antunes@ufabc.edu.br
}

Received 26 January 2018; Revised 28 March 2018; Accepted 17 April 2018; Published 29 May 2018

Academic Editor: Ramazan Solmaz

Copyright (C) 2018 Vanessa Mandarano Pinela et al. This is an open access article distributed under the Creative Commons Attribution License, which permits unrestricted use, distribution, and reproduction in any medium, provided the original work is properly cited.

\begin{abstract}
The AZ91D magnesium alloy was immersed in $3.5 \mathrm{wt} . \% \mathrm{NaCl}$ solution at room temperature for times ranging from $1 \mathrm{minute}$ up to 72 hours. The aim was to investigate the evolution of the corrosion process using confocal laser scanning microscopy (CLSM), electrochemical impedance spectroscopy, and X-ray photoelectron spectroscopy. The microstructure of the as-received alloy was initially characterized by optical microscopy and scanning electron microscopy (SEM). The crystalline phases were identified by $\mathrm{X}$-ray diffractometry. The main phases were primary- $\alpha$, eutectic- $\alpha$, and $\beta\left(\mathrm{Mg}_{17} \mathrm{Al}_{12}\right)$. Vickers microhardness markings were made on the surface of one etched sample to facilitate the identification of the same region at each different immersion time, thus enabling the observation of the corrosion process evolution. Corrosion initiates at the grain boundaries of the eutectic microconstituent and, then, propagates through primary $\alpha$-grains. The $\beta$-phase was less severely attacked.
\end{abstract}

\section{Introduction}

Weight reduction is a serious concern in the automotive and aerospace industries. Magnesium alloys are the state-of-theart materials when high strength-to-weight ratio is pursued. In this respect, they are gaining increasing interest for structural engineering applications [1-3]. Recyclability and good machinability are additional attributes that make them attractive materials to manufacture low weight parts [4]. In spite of these attractive attributes, the well-known chemical instability in aqueous environments is a core issue for magnesium alloys, limiting their applicability [5-7].

AZ91D is one of the most extensively used magnesiumbased alloys with consolidated applications in the automotive industry $[8,9]$. It is part of the $\mathrm{AZ}$ series, being alloyed with $\mathrm{Al}$ and $\mathrm{Zn}$. Typically, its microstructure is comprised of a mixture of magnesium- $\alpha$, an intermetallic $\beta$-phase rich in aluminum $\left(\mathrm{Mg}_{17} \mathrm{Al}_{12}\right)$, and an eutectic phase consisting of alternating lamellae of the $\alpha$ and $\beta$ phases [10,11]. The corrosion behavior of the alloy is markedly affected by its microstructural features. The relative complex mixture of different phases can give rise to regions with distinct chemical activities, thereby triggering the formation of local electrochemical microgalvanic cells, with preferential dissolution of the least noble phases [12-14]. The $\beta$-phase is reported to play a core role in this scenario. Its morphology and distribution within the magnesium matrix are key factors for the corrosion resistance of the AZ91D alloy. Large volume fractions and continuous distribution across the matrix are considered to be beneficial to the general corrosion resistance of the alloy by forming a protective layer of aluminum-rich surface oxide. By contrast, if it is discontinuous and concentrated in small areas due to its relative low volume fraction, it can accelerate galvanic corrosion effects, acting as local cathodes [15-18]. In spite of the knowledge accumulated so far and the consensus on the critical role of the $\beta$-phase, several authors have recently highlighted the need for further studies on the corrosion mechanism of $\mathrm{Mg}$-Al alloys in order to expand and consolidate their engineering applications [19-22].

Confocal laser scanning microscopy (CLSM) is a powerful tool for investigating the onset of corrosion processes at 


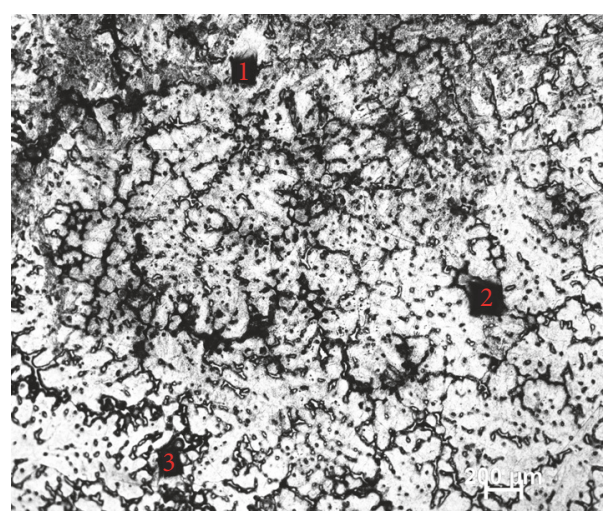

FIGURE 1: CLSM micrograph showing the Vickers impressions on the surface of the etched AZ91D alloy.

either in situ or ex situ conditions [23]. The high magnification and relative short acquisition times can be advantageously exploited in the corrosion field [24]. CLSM was successfully employed to study local corrosion process in aluminum and nickel alloys $[25,26]$. Investigations devoted to corrosion of welded joints of high strength steels and pitting corrosion of stainless steels have been reported [27-30]. Notwithstanding, in spite of the increasing interest of magnesium alloys for structural applications, CLSM studies are hardly reported for elucidating the onset of corrosion processes of magnesium alloys in aqueous environments.

In this work, CLSM was employed to investigate the onset of corrosion processes of the AZ91D during short immersion times in 3.5 wt.\% $\mathrm{NaCl}$ solution at room temperature. The alloy microstructure was initially characterized by optical and scanning electron microscopy (SEM). Corrosion evolution was monitored up to $72 \mathrm{~h}$ of immersion.

\section{Materials and Methods}

2.1. Material and Sample Preparation. A die-cast ingot of the AZ91D magnesium alloy (nominal composition in wt.\% 8.3-9.7\% Al, 0.35-1.00\% Zn, Mn > 0.15\%, Si < 0.10\%, Fe < $0.005 \%, \mathrm{Cu}<0.03 \%, \mathrm{Ni}<0.002 \%, \mathrm{Mg}$ balance) was kindly provided by Rima Industrial Magnésio S.A. (Brazil). Small square-shaped samples $\left(0.50 \mathrm{~cm}^{2}\right)$ were cut from the as-cast ingot using a conventional metallographic cut-off machine. The samples were embedded in phenolic resin. Next, surface preparation was carried out by sequential grinding with waterproof $\mathrm{SiC}$ paper up to grit \#1000, followed by polishing with diamond paste $(6 \mu \mathrm{m})$. After washing with distilled water and ethanol the samples were chemically etched in a solution comprised of a mixture of glacial acetic acid, ethanol, and distilled water for $10 \mathrm{~s}$. Next, the samples were washed with distilled water and dried in a warm air stream provided by a conventional air blowing gun.

Vickers microhardness indentation tester (EQUILAM HVS-1000) was employed to produce surface marking on the etched samples in order to allow for identifying the same region of the microstructure when subjecting the samples to CLSM analysis. Hence, three impressions were made using $1 \mathrm{~kg}$ load as shown by a representative micrograph displayed

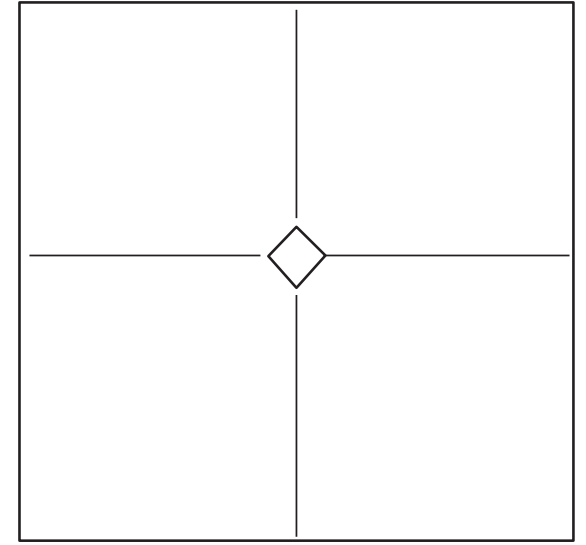

FIGURE 2: Schematic representation of the different quadrants evaluated around each Vickers impression mark.

in Figure 1. The marked regions were, thereafter, employed as a guide to register micrographs of the same region for the samples subjected to corrosion for different times. For each impression mark four different quadrants were evaluated to investigate the evolution of the corrosion process, as schematically shown in Figure 2. The impression mark is at the center of the figure and the evolution of the corrosion process of the AZ91D alloy was prospected at each one of the four quadrants. Thus, twelve different regions were evaluated for each immersion time.

2.2. Microstructural Characterization. X-ray diffraction (XRD) analysis was carried out to identify the crystalline phases of the AZ91D alloy using a Rigaku diffractometer (Multiflex, $40 \mathrm{kV}, 20 \mathrm{~mA}$ ) operating with $\mathrm{Cu}-\mathrm{k} \alpha$ radiation in the $\theta-2 \theta$ geometry. The analysis was performed in the range from 20 to $90^{\circ}$. SEM micrographs were obtained to examine to morphology of the different phases (JEOL JMS-6010LA). Elemental composition was determined by energy dispersive $\mathrm{X}$-ray analysis (EDS).

2.3. Immersion Test. Samples prepared as described in Section 2.1 were immersed in $3.5 \mathrm{wt}$. $\% \mathrm{NaCl}$ solution at room temperature for the following times: 1 minute, 5 minutes, 


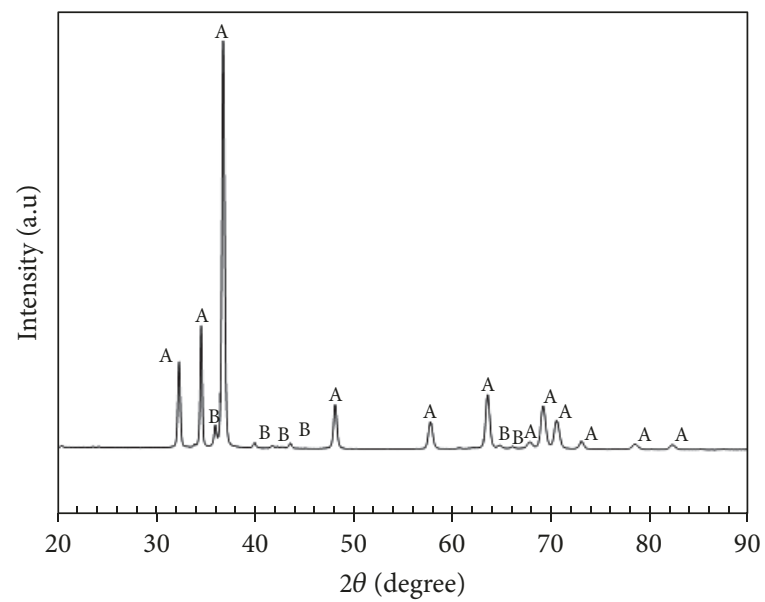

A: $\alpha-\mathrm{Mg}$

B: $\beta-\mathrm{Mg}_{17} \mathrm{Al}_{12}$

FIGURE 3: XRD pattern of the AZ91D magnesium alloy.

10 minutes, 20 minutes, 30 minutes, 50 minutes, 3 hours, 6 hours, 15 hours, 40 hours, and 72 hours. Only the results obtained for the samples immersed for 1 minute, 30 minutes, 3 hours, 6 hours, 15 hours, 40 hours, and 72 hours are presented. The surface morphologies of samples immersed for 5 minutes, 10 minutes, and 20 minutes are very similar to that observed after 1 minute. In the same respect, the surface morphology of the sample immersed for 50 minutes was very similar to that observed after 30 minutes. As consequence, these micrographs of samples immersed for 5 minutes, 10 minutes, 20 minutes, and 50 minutes are not presented throughout the text. After immersion, the sample was removed from the testing solution, washed with distilled water, dried in a warm air stream, and promptly subjected to CLSM analysis (Olympus OLS4100). The evolution of the corrosion process was accompanied by observing the same region of the microstructure at each time, using the hardness impressions as guides to locate the region of interest.

2.4. Electrochemical Impedance Spectroscopy (EIS). EIS measurements were carried out to evaluate the electrochemical behavior of the AZ91D upon immersion in $3.5 \mathrm{wt} \% \mathrm{NaCl}$ solution at room temperature. The data were acquired after the same immersion times evaluated during the immersion test (Section 2.3) in order to complement the characterization of the evolution of the AZ91D corrosion process. A conventional three-electrode cell setup was used for the measurements with a platinum wire as the counter-electrode, Ag/ $\mathrm{AgCl}$ as reference, and the AZ91D alloy as the working electrode. A small sinusoidal perturbation signal was employed with amplitude of $\pm 10 \mathrm{mV}$ ( $\mathrm{rms}$ ) in the frequency range from $100 \mathrm{kHz}$ to $1 \mathrm{~Hz}$ and acquisition of 10 points per frequency decade. The tests were conducted using an Autolab M101 potentiostat/galvanostat.

2.5. X-Ray Photoelectron Spectroscopy (XPS). XPS surface mapping was employed to check the distribution of $\mathrm{Mg}, \mathrm{Al}$ and $\mathrm{O}$ on the surface of the AZ91D alloy after immersion for different times in $3.5 \mathrm{wt} . \% \mathrm{NaCl}$ solution at room temperature. The immersion times were the same employed for the immersion test described in Section 3.2. The spectra were obtained using a ThermoFisher Scientific K-alpha+ spectrometer operating with a monochromatic Al-k $\alpha$ radiation source. The spot size was $80 \mu \mathrm{m}$. The area map was defined with $16 \times 10$ points (approximately $3.0 \mathrm{~mm}^{2}$ ).

\section{Results and Discussion}

3.1. Structural Characterization. Figure 3 shows the XRD pattern of the AZ91D alloy. The main crystalline phase is the magnesium matrix $\alpha$-Mg. The presence of the intermetallic $\mathrm{Mg}_{17} \mathrm{Al}_{12}$ ( $\beta$-phase) is unequivocally identified. These results are in agreement with the literature $[31,32]$.

The alloy microstructure is displayed in the CLSM micrographs shown in Figure 4. A general view is shown in Figure 4(a) whereas a more detailed representation is seen in Figure 4(b). The microstructure consists of a mixture of $\alpha-\mathrm{Mg}$, lamellar eutectic microconstituent along the grain boundaries of the magnesium matrix and $\beta-\mathrm{Mg}_{17} \mathrm{Al}_{12}$ as labeled in Figure 4(b). These features are typical of the AZ91D alloy [33, 34]. Microstructure was further characterized by SEM and EDS analysis. The SEM micrograph shown in Figure 5(a) reveals the different microconstituents of the AZ91D alloy. Their elemental composition was checked by EDS analysis. Mapping analyses for $\mathrm{Al}$ and $\mathrm{Mg}$ are displayed in Figures 5(b) and 5(c), respectively. It is seen that aluminum is enriched in the eutectic region with respect to the matrix. Yet, it is mainly present in the $\beta$-phase whereas the magnesium signal is much more intense in $\alpha-\mathrm{Mg}$. As inferred from the literature, compositional differences between each phase can give rise to regions with distinct chemical activities and, therefore, promote the formation of microgalvanic cells that trigger corrosion process of the alloy [19].

The results presented in this section were allowed to fully characterize the as-cast microstructure of the AZ91D. Next, the evolution of its corrosion process is discussed based on 


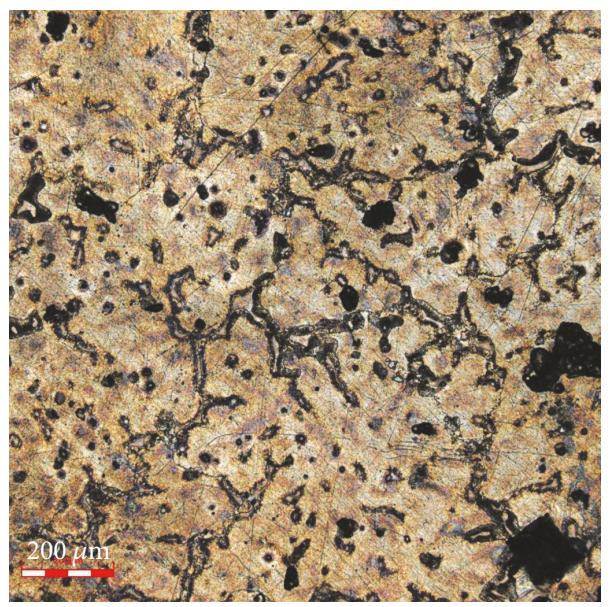

(a)

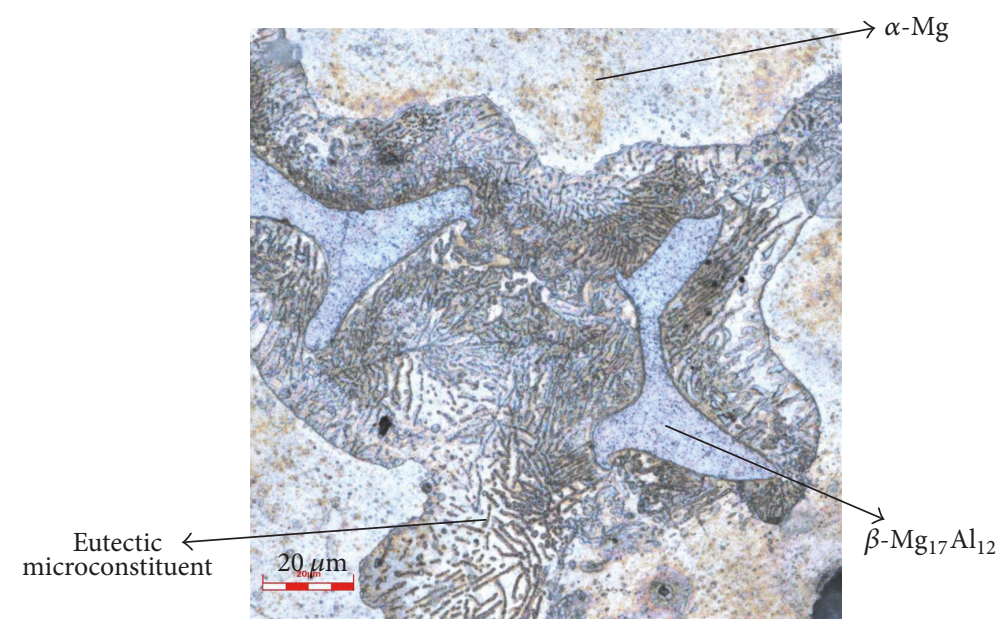

(b)

Figure 4: CLSM micrographs of the AZ91D alloy: (a) general view; (b) detailed view.

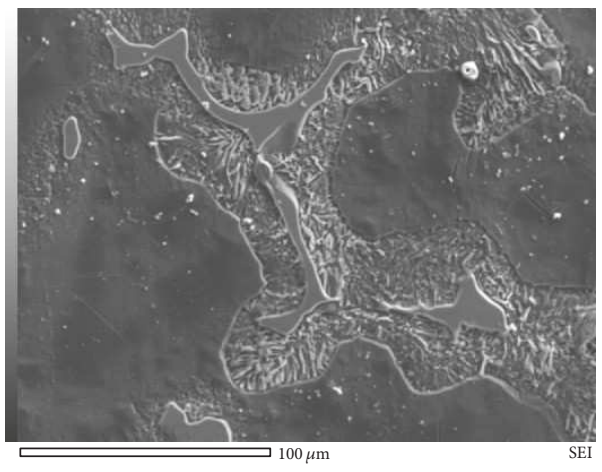

(a)

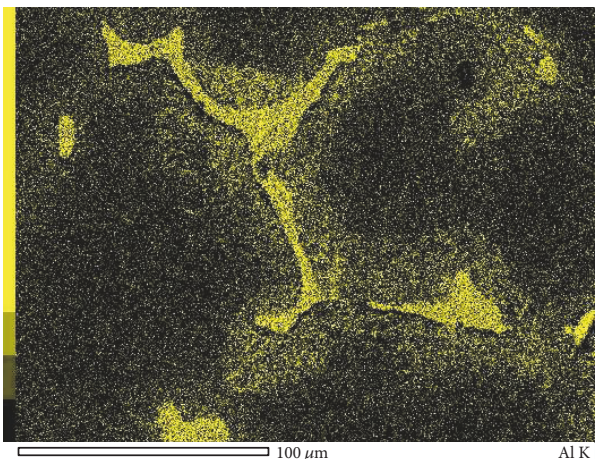

(b)

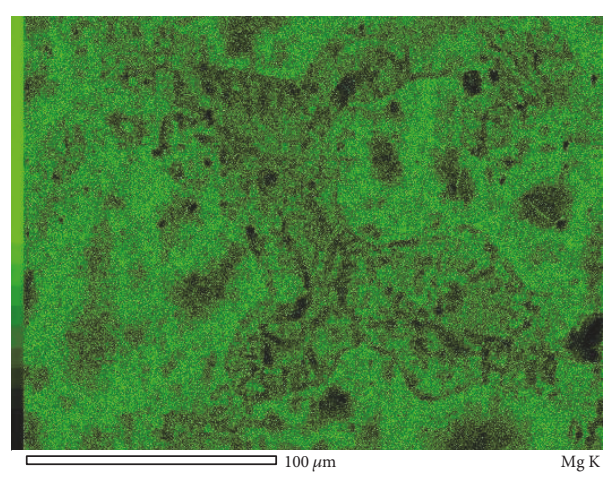

(c)

FIgURE 5: (a) SEM micrograph of the AZ91D alloy; (b) EDS mapping analysis for Al; (c) EDS mapping analysis for Mg.

CLSM analyses carried out in accordance with the immersion test described in Section 2.3.

3.2. Immersion Test. Figure 6 shows CLSM micrographs of the AZ91D alloy immersed for up to $3 \mathrm{~h}$ in $3.5 \mathrm{wt} . \% \mathrm{NaCl}$ solution at room temperature. The Vickers microhardness impression is seen at the bottom right of each micrograph. It is somewhat attacked during the chemical etching procedure employed to reveal the alloy microstructure. The general microstructure can be perceived in the as-received condition (Figure 6(a)). It was little affected by the $\mathrm{NaCl}$ solution up to $3 \mathrm{~h}$ of immersion. As shown in Section 3.1, the brighter regions are related to the presence of eutectic- $\alpha$ and $\beta$ $\mathrm{Mg}_{17} \mathrm{Al}_{12}$. At this time, corrosion spots were formed as indicated by the small stained region at the lower right part of the micrograph (pointed by the red circle in Figure 6(d)). 


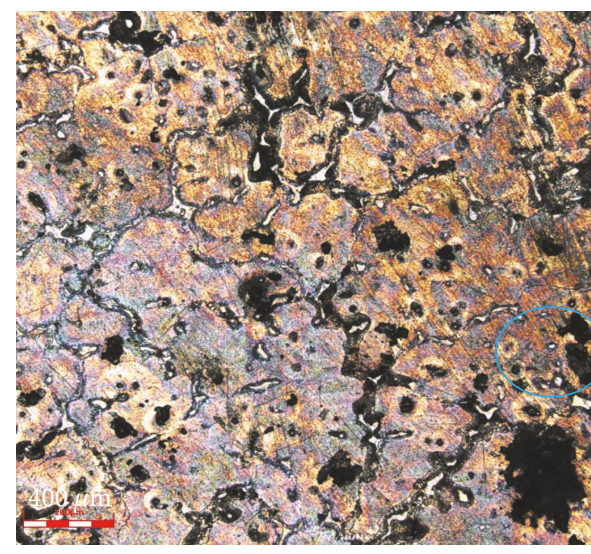

(a)

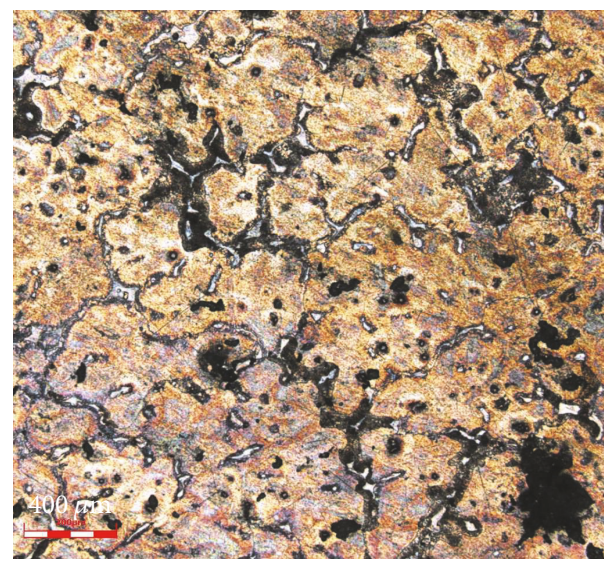

(c)

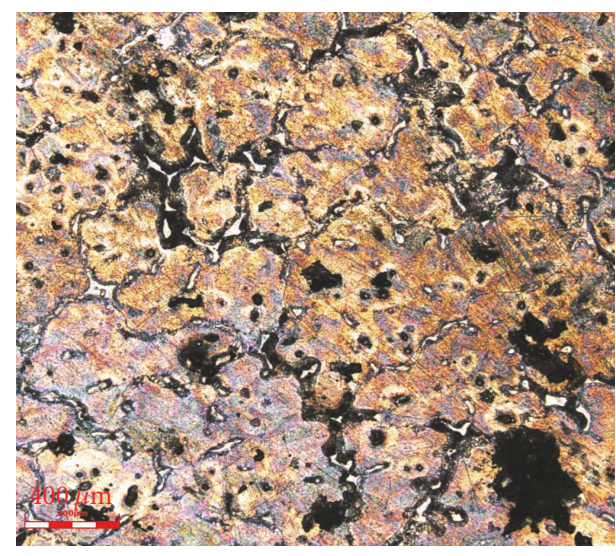

(b)

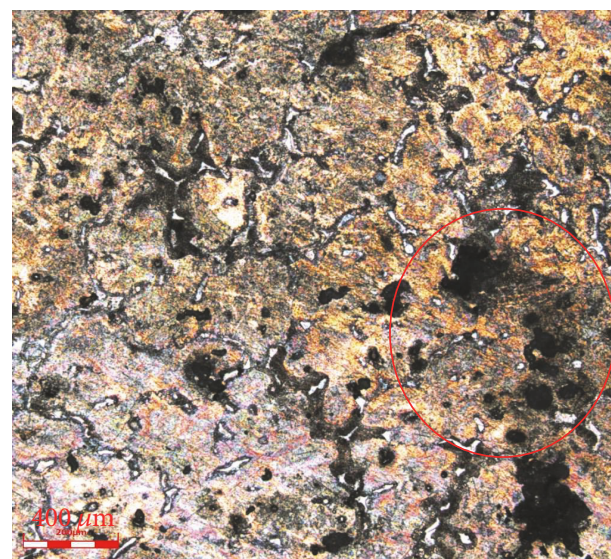

(d)

FIGURE 6: CLSM micrographs of the AZ91D alloy immersed for different times in $3.5 \mathrm{wt} . \% \mathrm{NaCl}$ solution at room temperature: (a) as-received; (b) $1 \mathrm{~min}$; (c) $30 \mathrm{~min}$; (d) $3 \mathrm{~h}$.

Interestingly, this part of the microstructure presents discontinuous distribution of the $\beta$-phase when compared to the upper left part of the micrograph. According to the literature, $\beta$-phase morphology is closely related to the onset of corrosion processes of the AZ91D alloy. When it is evenly distributed within the $\alpha$-Mg matrix, it acts as a barrier against dissolution. If, in turn, it is discontinuous as observed in the region where corrosion spots started to appear, it triggers the formation of microgalvanic cells that drive the localized corrosion attack $[15,16]$. Our results point that this mechanism took place for the AZ91D alloy and could be perceived after $3 \mathrm{~h}$ of immersion in the electrolyte.

The evolution of the corrosion process was accompanied up to $72 \mathrm{~h}$. Figures $7(\mathrm{a})-7$ (d) show CLSM micrographs of the same region observed in Figure 6. The micrographs were acquired after $6 \mathrm{~h}, 15 \mathrm{~h}, 40 \mathrm{~h}$, and $72 \mathrm{~h}$ of immersion in $3.5 \mathrm{wt} . \% \mathrm{NaCl}$ solution at room temperature. Corrosion spread out slowly. New stained areas are visible after $40 \mathrm{~h}$ (Figure 7(c)). Intensively corroded areas were found after $72 \mathrm{~h}$, propagating from right to left (Figure $7(\mathrm{~d})$ ). It is noteworthy, though, that some regions remained unaffected by corrosion even after $72 \mathrm{~h}$ of immersion. Such regions are mainly the brighter parts of the microstructure, wherein the $\beta$-phase is more evenly distributed. Notwithstanding, corrosion seems to spread even at the $\beta$-phase after $72 \mathrm{~h}$ (Figure 7(d)).

The morphological features of the corrosion process are not as marked up to $15 \mathrm{~h}$ of immersion as they are for $40 \mathrm{~h}$ and $72 \mathrm{~h}$. In this respect, in order to give a more clear interpretation of the corrosion spots formed at first hours of immersion, transverse profiles were obtained from the CSLM micrographs as shown in Figure 8 for the as-received condition (Figure 6(a)) and for the specimen immersed for $15 \mathrm{~h}$ in $3.5 \mathrm{wt} . \% \mathrm{NaCl}$ solution at room temperature (Figure 7(b)). These lines were taken from the lower part of the CLSM micrographs shown in Figures 6(a) and 7(b) for the as-received and $15 \mathrm{~h}$ conditions, respectively. It is important to mention, though, that the first corrosion spots were observed after $3 \mathrm{~h}$ of immersion, as shown in Figure $6(\mathrm{~d})$, and the micrograph from the $15 \mathrm{~h}$ condition (Figure $7(\mathrm{~b})$ ) was chosen only to exemplify how the transverse profile of the corroded area appears when evaluated using the CLSM measuring tool.

The profiles show the more intense variation of the height for the specimen immersed for $15 \mathrm{~h}$. Moreover, it is clear that a depressive region appear at right for the $15 \mathrm{~h}$ condition as indicated by the black circle. Such region was not observed in 


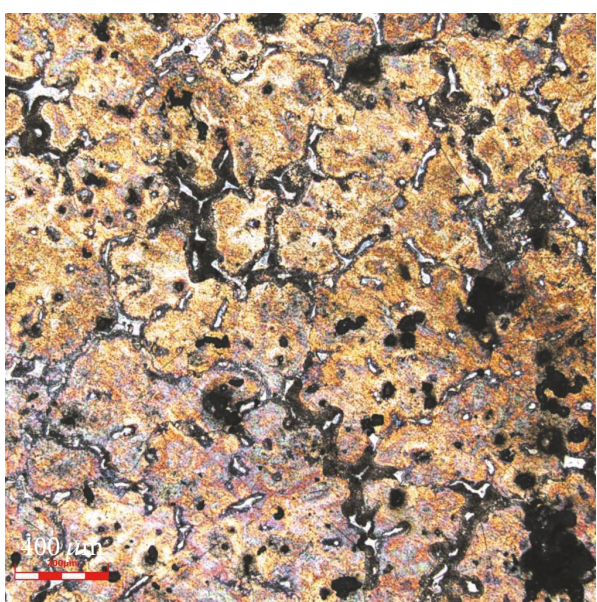

(a)

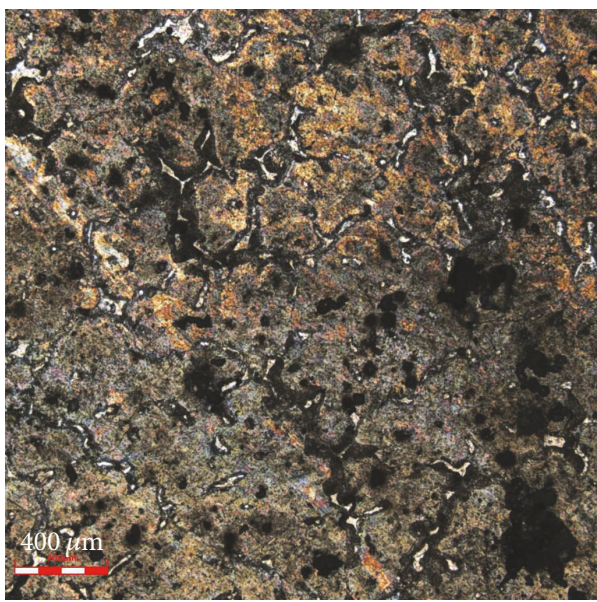

(c)

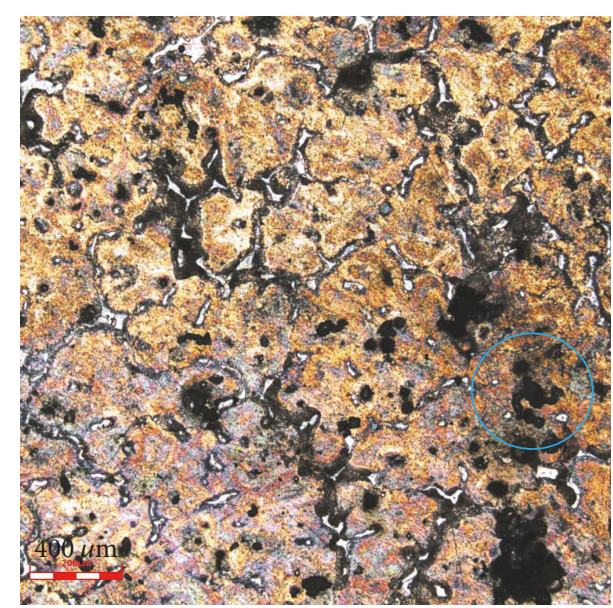

(b)

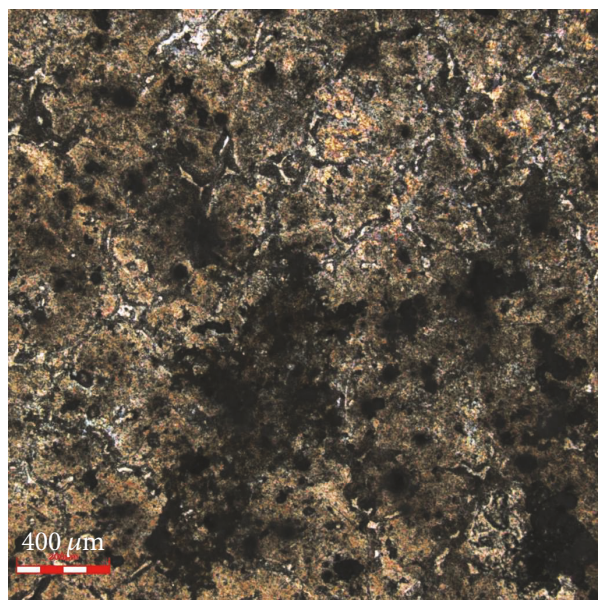

(d)

FIGURE 7: CLSM micrographs of the AZ91D alloy immersed for different times in $3.5 \mathrm{wt} . \% \mathrm{NaCl}$ solution at room temperature: (a) $6 \mathrm{~h}$; (b) $15 \mathrm{~h}$; (c) $40 \mathrm{~h}$; (d) $72 \mathrm{~h}$.

the profile obtained for the as-received alloy. At this point, it is important to correlate these profiles with the corresponding microstructures so that the corroded areas can be clearly related to the height variation in the $z$-axis. Hence, the blue circles shown in Figures 6(a) and 7(b) were inserted to indicate their corresponding regions in the transverse profiles displayed in Figures 8(a) and 8(b), respectively.

By carefully examining the CLSM micrographs for the as-received and $15 \mathrm{~h}$ immersed alloy and their corresponding transverse profiles at the regions marked in Figures 6(a) and 7(b), it is noteworthy that the depressive region marked by the black circle in Figure 8(a) corresponds to the region where the corrosion spots firstly appear in the AZ91D microstructure. This corroded region was perceived after $3 \mathrm{~h}$ of immersion (Figure 6(d)). CLSM analysis aimed to successfully indicate the onset of corrosion spots by combining their visual identification at the micrograph with the quantitative evaluation of the surface profile.

Notwithstanding, in spite of the interpretation given a bove, the micrographs shown in Figures 6 and 7 did not allow one to clearly identify the microstructural features related to the onset of corrosion. Higher magnification micrographs are needed to show the corroded regions in detail, allowing identification of the different phases of the AZ91D alloy. In this regard, higher magnification CLSM micrographs of the AZ91D alloy immersed for $6 \mathrm{~h}, 15 \mathrm{~h}, 40 \mathrm{~h}$, and $72 \mathrm{~h}$ in $3.5 \mathrm{wt} . \%$ $\mathrm{NaCl}$ solution at room temperature are shown in Figures 9(a)-9(d). These periods were selected as the initial corrosion spots and their evolution could be promptly examined from their micrographs. Shorter immersion times did not allow an unequivocal visualization of the initial corrosion sites.

Figure 9(a) shows dark points indicating the onset of corrosion mainly at the grain boundaries of the eutectic microconstituent, along with the boundaries of the $\beta$-phase. The $\beta$-phase, in turn, is not affected. After $15 \mathrm{~h}$ of immersion (Figure 9(b)), it remains unaffected, but there were several dark spots indicating corrosion within the $\alpha-\mathrm{Mg}$ matrix and also at the eutectic microconstituent. This scenario holds up to $40 \mathrm{~h}$ of immersion (Figure $9(\mathrm{c})$ ). Corrosion propagated throughout the whole microstructure after $72 \mathrm{~h}$ (Figure $9(\mathrm{~d})$ ). 


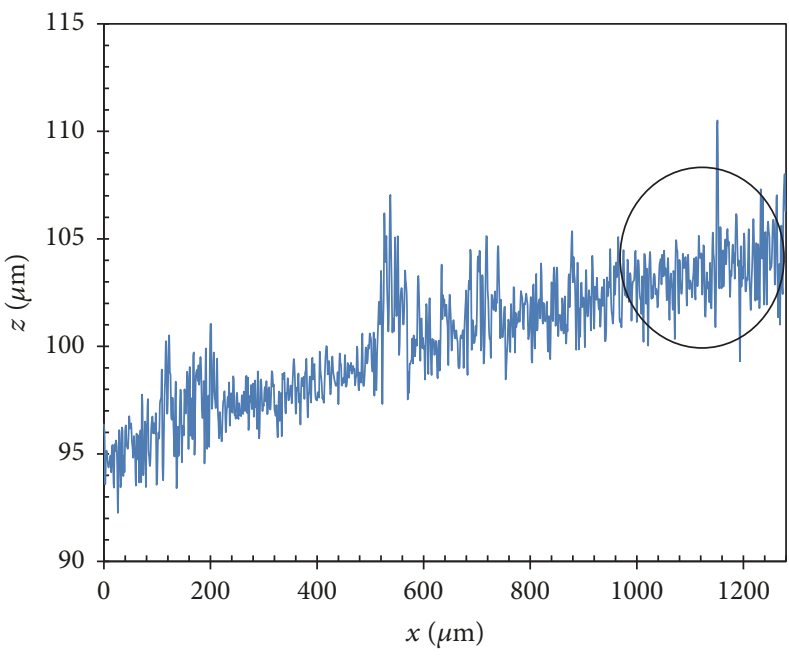

(a)

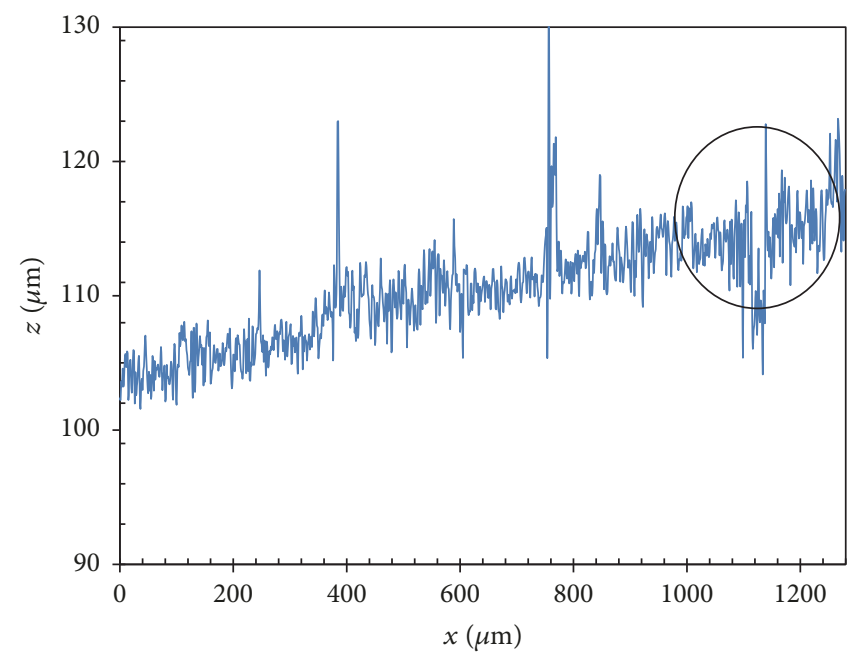

(b)

FIGURE 8: Transverse profiles obtained from the CLSM micrographs of the AZ91D alloy: (a) the as-received condition; (b) after immersion for $15 \mathrm{~h}$ in $3.5 \mathrm{wt} . \% \mathrm{NaCl}$ solution at room temperature.

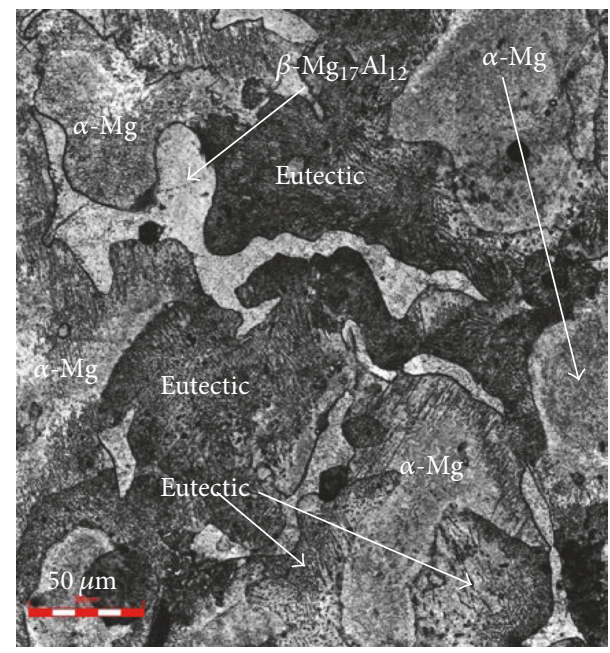

(a)

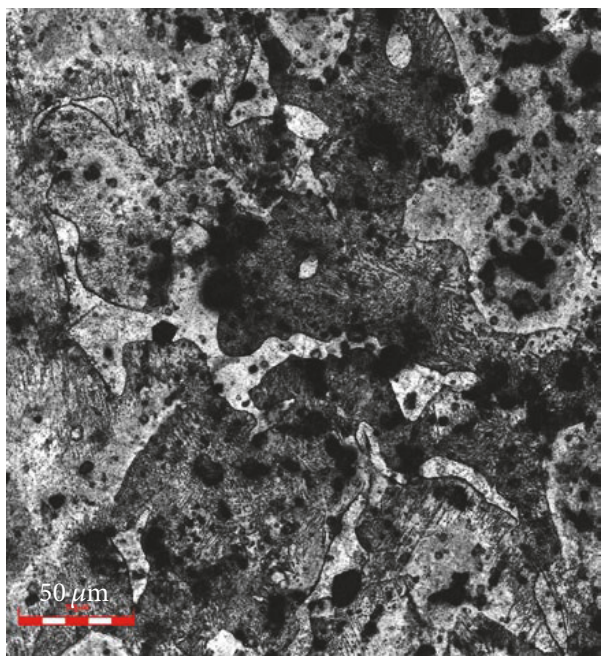

(c)

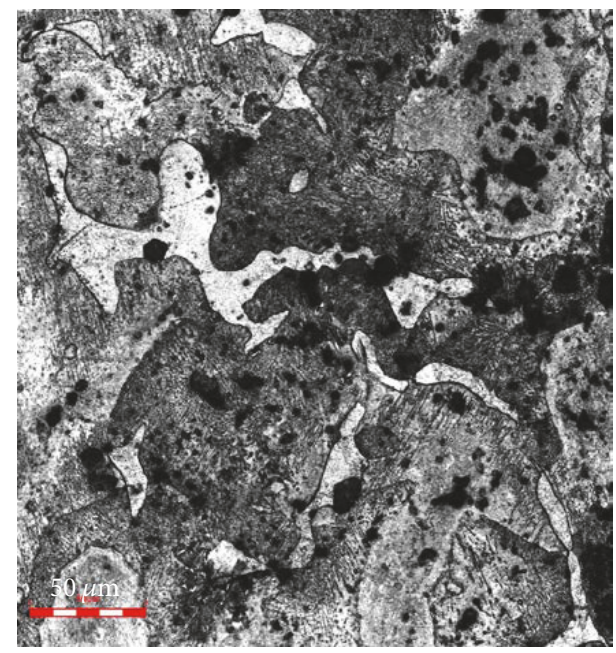

(b)

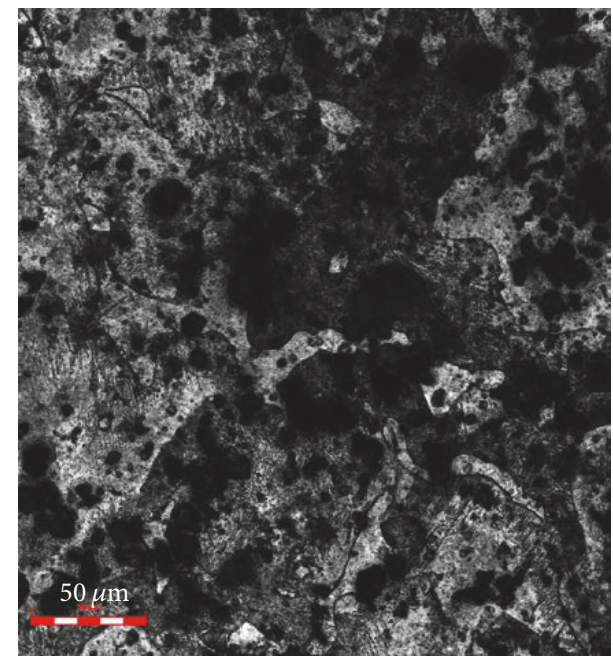

(d)

FIGURE 9: CLSM micrographs showing the evolution of the corrosion process of the AZ91D alloy in $3.5 \mathrm{wt} . \% \mathrm{NaCl}$ solution at room temperature: (a) $6 \mathrm{~h}$; (b) $15 \mathrm{~h}$; (c) $40 \mathrm{~h}$; (d) $72 \mathrm{~h}$. 
The $\beta$-phase was also dissolved. The eutectic microconstituent was severely attacked as well as the $\alpha$-Mg matrix.

The evolution of the corrosion process can be checked by examining 3D CLSM micrographs of the AZ91D alloy and the corresponding roughness profile along specific lines. This is exemplified in Figures 10(a)-10(c) for the AZ91D alloy immersed for $6 \mathrm{~h}, 15 \mathrm{~h}$, and $72 \mathrm{~h}$ in $\mathrm{NaCl} 3.5 \mathrm{wt} . \%$ at room temperature.

\subsection{Electrochemical Impedance Spectroscopy (EIS). EIS dia-} grams of the AZ91D alloy immersed in 3.5 wt. $\% \mathrm{NaCl}$ solution at room temperature for different times are shown in Figure 11.

Nyquist plots (Figure 11(a)) are characterized by capacitive loops whose diameters depend on the immersion time. It is well-known that the capacitive loop diameter is associated with the charge transfer resistance of the electrode surface, being, therefore, related to its corrosion resistance $[35,36]$. In this respect, its evolution with the immersion can be an indication of the corrosion reactions taking place on the alloy surface. From Figure 11(a) one can observe that there is a marked decrease of the impedance values from the $1 \mathrm{~min}$ condition up to $3 \mathrm{~h}$. The capacitive loops of the $30 \mathrm{~min}$ and $3 \mathrm{~h}$ conditions are very small compared to the $1 \mathrm{~min}$ loop. Thus, in order to more clearly observe them with respect to the other immersion times, the inset of Figure 11(a) shows the Nyquist plots with expanded scales. This would indicate that corrosion reactions are taking place right after immersion in the electrolyte. As a consequence, the alloy surface becomes oxidized. This, in turn, would lead to the formation of a thicker oxide layer, giving rise to an impedance rise which is confirmed by the increase of the capacitive loop diameter for the $6 \mathrm{~h}$ and $15 \mathrm{~h}$ immersion times. It is noteworthy that the onset of visual corrosion spots were observed for these times, as described in Section 3.2.

Additional evidence for the reasoning derived from the Nyquist plots can be achieved by evaluating the Bode plots shown in Figure 11(b). The phase angles are highly resistive at low frequencies up to $3 \mathrm{~h}$ of immersion, being very distant from the ideal capacitive response at $-90^{\circ}$ which denotes the propensity of the electrode surface to charge transfer reactions [37]. As corrosion proceeds, the phase angles rise up to $-40^{\circ}$ and $-50^{\circ}$ for the $6 \mathrm{~h}$ and $15 \mathrm{~h}$ conditions, leading to a more capacitive response with the development of a more intensively corroded layer. However, as this layer is not compact, it is not protective against corrosion and the phase angles decrease at the low frequencies for the $40 \mathrm{~h}$ immersion condition. A new rise toward more capacitive values is found after $72 \mathrm{~h}$ as a consequence of the intensified corrosion process. EIS proved to be very sensitive to the evolution of the corrosion process on the AZ91D, allowing one to correlate its results with those obtained from the immersion test (Section 3.2). Further information on the composition of the corroded layer and its correlation with the immersion time was obtained by XPS analysis, as described in the next section.

3.4. X-Ray Photoelectron Spectroscopy (XPS). XPS mapping was used to elucidate the elemental distribution of magnesium, aluminum and oxygen over the AZ91D surface at the same immersion times evaluated by CLSM and EIS. The results are shown in Figures 12-19. The data are expressed as quantified atomic percentage XPS maps for Mg1s, O1s, and Al2p. Only these signals were detected in significant quantities on the surface of the AZ91D alloy independently of the immersion time. The maps were interpolated up to an equivalent $128 \times 128$ pixel density using the Avantage software $@$.

The maps for the as-received alloy (Figure 12) show that $\mathrm{Al} 2 \mathrm{p}$ is present up to 9.0 at $\%$ in some areas whereas small regions present a very small amount. For the most part of the area the atomic concentration of $\mathrm{Al} 2 \mathrm{p}$ is near the highest value of the scale. Mgls predominates across the whole surface but it is less intense where the O1s signal is more intense. The O1s signal reaches a maximum of 39.7 at.\%.

This scenario promptly changes after 1 minute of immersion (Figure 13). The Al2p maximum signal decreased to 6.37 at.\% whereas that of O1s increased to 56.7 at.\%. The Mg1s signal became less intense over the upper part of the area where the O1s signal is the most intense. XPS mapping indicates that the surface of the AZ91D alloy became more oxidized right after 1 minute of immersion in $3.5 \mathrm{wt} . \% \mathrm{NaCl}$ solution at room temperature.

This trend was intensified for the sample immersed for 30 minutes (Figure 14). The area where the Al2p signal is weak increased with respect to the as-received alloy (Figure 14(a)). The O1s signal, in turn, is strong over a bigger part of the probed area (Figure 14(b)) whereas the Mg1s atomic concentration is at the lowest level of the scale in most part of the area (Figure 14(c)).

As corrosion proceeds for longer times the O1s signal remains high over the whole area for $3 \mathrm{~h}$ and $6 \mathrm{~h}$ of immersion (Figures 15(b) and 16(b)) whereas the signal of Al2p is weak (Figures 15(a) and 16(a)). The Mg1s signal does not follow a clear trend, being less intense at $6 \mathrm{~h}$ (Figure 16(c)) than at $3 \mathrm{~h}$ (Figure 15(c)). For the sample immersed for $15 \mathrm{~h}$, though, the Ols atomic concentration is relatively high and spreads over almost the whole surface (Figure 17(b)) whereas the signals from Mg1s (Figure 17(c)) and Al2p (Figure 17(a)) are relatively weak over it. The high fraction of the O1s signal for this condition allows one to hypothesize that the impedance increase observed from $6 \mathrm{~h}$ to $15 \mathrm{~h}$ of immersion (Figure 11(a)) is actually due to the formation of a more spread oxide layer on the surface of the AZ91D alloy after $15 \mathrm{~h}$.

After $40 \mathrm{~h}$ of immersion the Al2p signal (Figure 18(a)) seems to be more spread over the whole surface than at $15 \mathrm{~h}$. The Mg1s signal (Figure 18(c)) is more intense than at $15 \mathrm{~h}$ whereas the O1s signal presents an opposite trend. For the $72 \mathrm{~h}$ condition the Al2p signal decreased with respect to the $40 \mathrm{~h}$ condition (Figure 19(a)), the O1s signal increased (Figure 19(b)), and the Mg1s signal decreased (Figure 19(c)).

The more intense Al2p and Mgls signals observed for the sample immersed for $40 \mathrm{~h}$ can be related to the lower impedance values of this condition when compared to the sample immersed for $15 \mathrm{~h}$ (Figure 11(a)). In this respect, the charge transfer reactions would take place at the electrode surface due to the incipient protective oxide layer formed during immersion. This layer would be deteriorated from $15 \mathrm{~h}$ to $40 \mathrm{~h}$, exposing more aluminum and magnesium to the $\mathrm{NaCl}$ solution. As a consequence, the impedance values are 

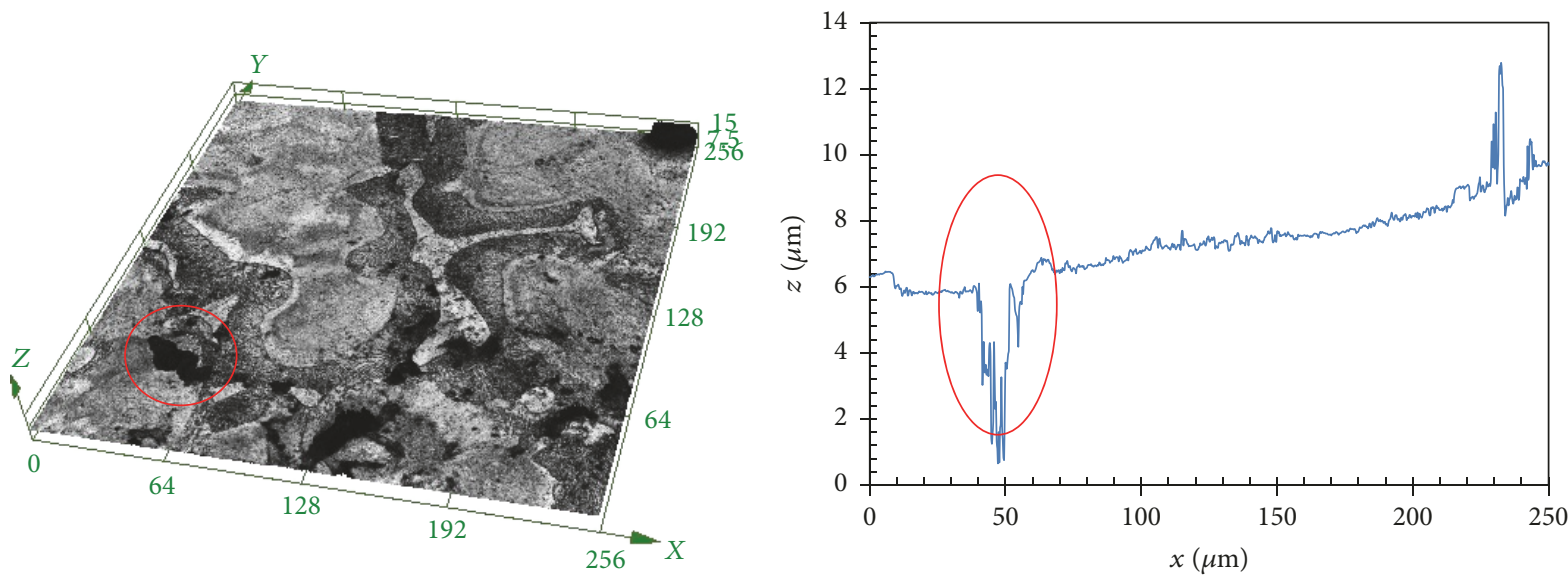

(a)
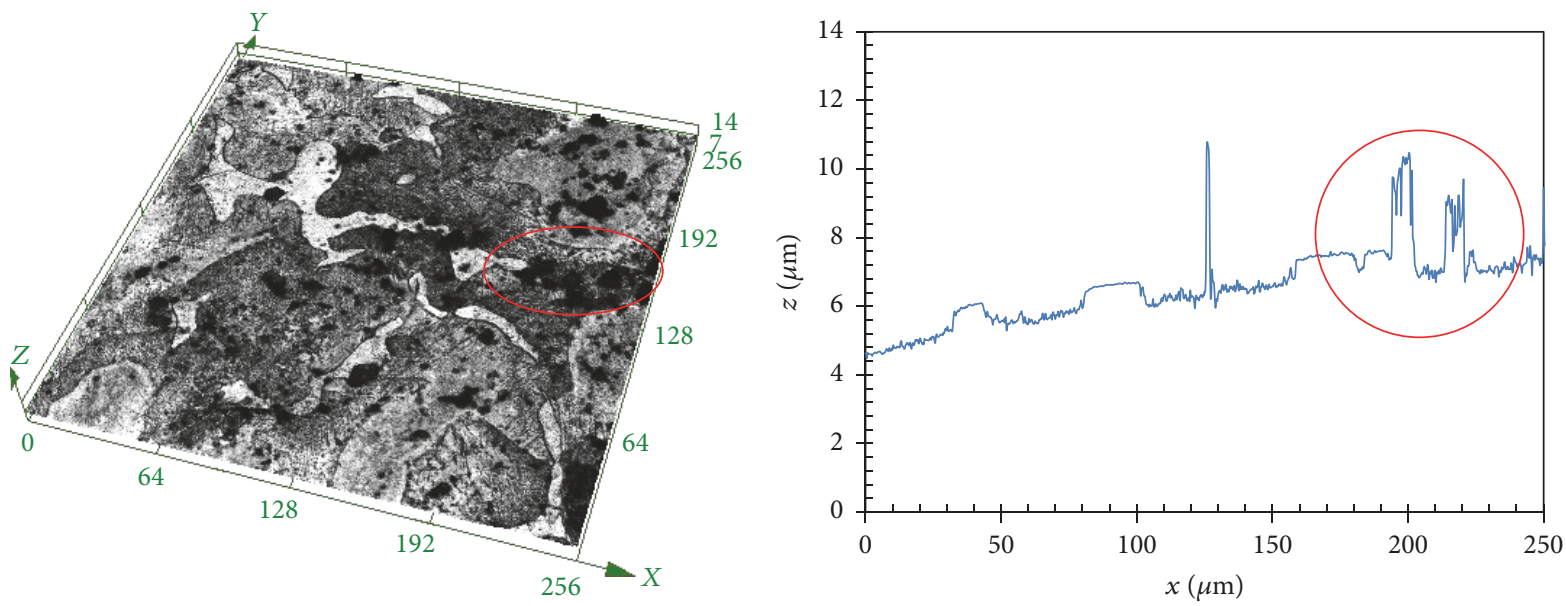

(b)
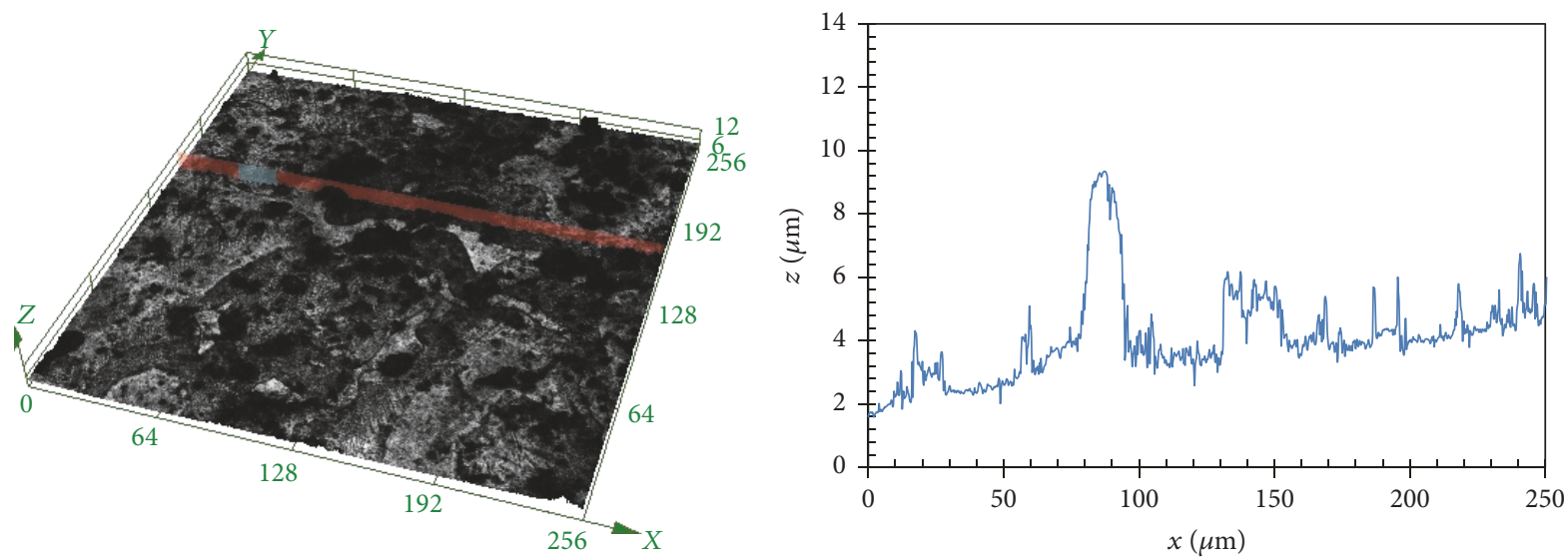

(c)

FIGURE 10: CLSM 3D images and corresponding roughness profiles for the AZ91D immersed in $3.5 \mathrm{wt} . \% \mathrm{NaCl}$ solution for different times: (a) $6 \mathrm{~h}$; (b) $15 \mathrm{~h}$; (c) $72 \mathrm{~h}$.

low at $40 \mathrm{~h}$ than at $15 \mathrm{~h}$. Next, as the oxidation process evolves on the surface of the AZ91D alloy, the oxygen signal becomes more intense and the oxide layer formed at $72 \mathrm{~h}$ would lead to an increase of the impedance values with respect to the $40 \mathrm{~h}$ period, as observed in Figure 11(a).
XPS mapping and EIS measurements gave valuable results, regarding the chemical stability and composition of the oxide layer formed on the surface of the AZ91D alloy upon the first hours of immersion in $3.5 \mathrm{wt} . \% \mathrm{NaCl}$ solution at room temperature. However, they do not allow identification 


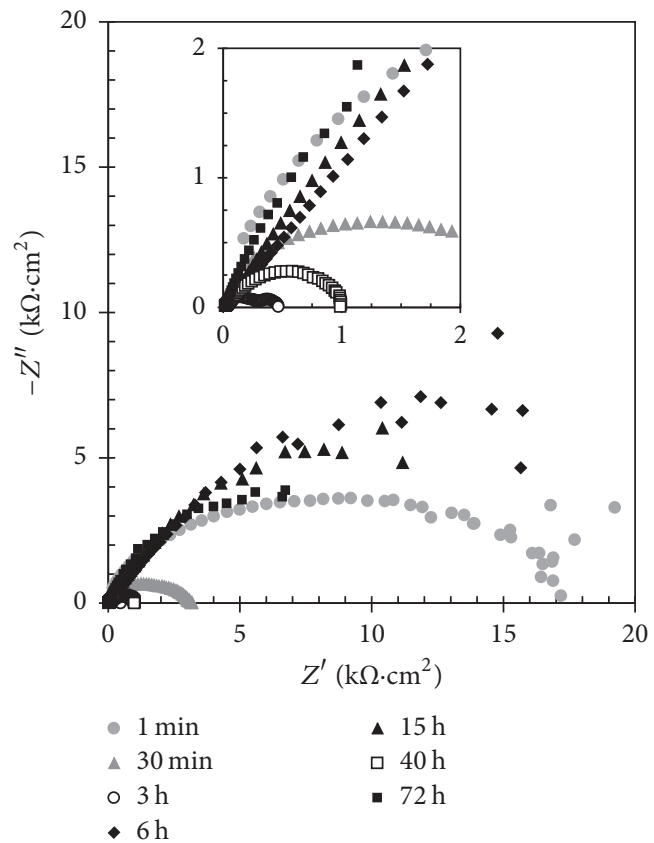

(a)

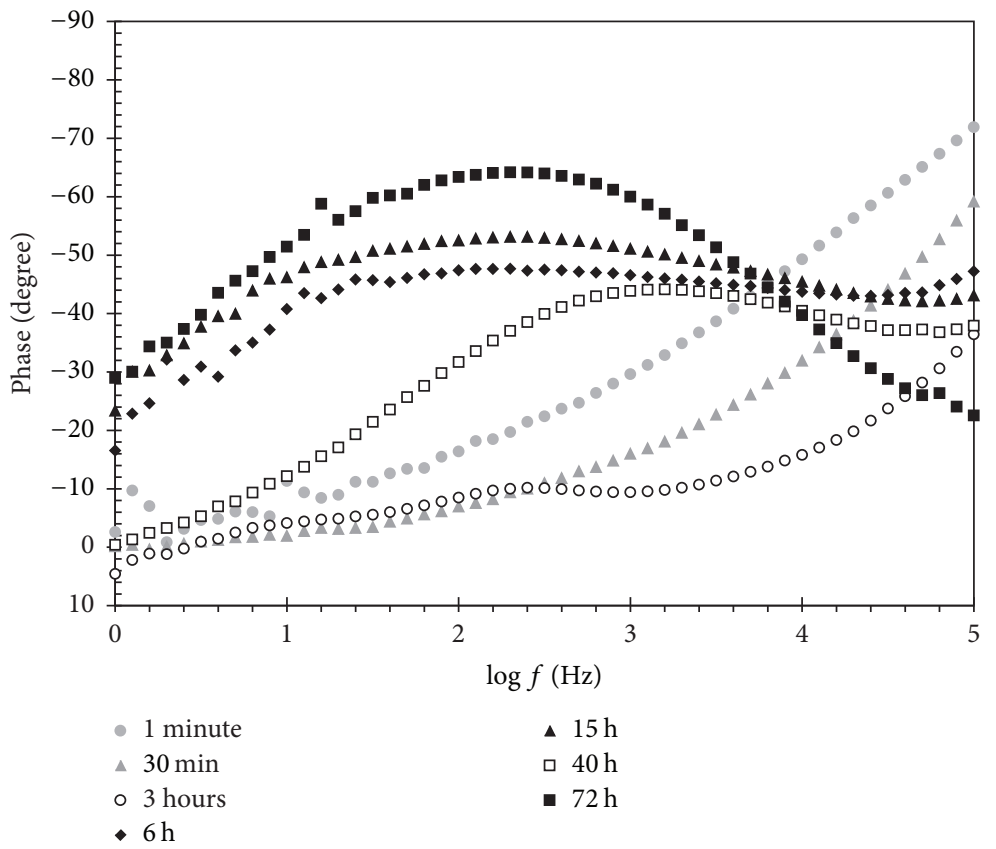

(b)

FIGURE 11: EIS diagrams of the AZ91D alloy immersed in $3.5 \mathrm{wt} . \% \mathrm{NaCl}$ solution at room temperature for different times: (a) Nyquist and (b) Bode (phase angle versus $\log f$ ) plots.

of the microstructural features associated with the first corrosion spots as CLSM does. In this respect, coupling these techniques is an interesting route to understand the corrosion process of the AZ91D alloy.

\section{Conclusions}

The evolution of the corrosion process of the AZ91D magnesium alloy was examined by CLSM during the first hours of immersion in $3.5 \mathrm{wt} . \% \mathrm{NaCl}$ solution at room temperature. This technique proved to be a valuable tool for assessing the onset of corrosion spots in the alloy microstructure. Corrosion started at the interface between the eutectic microconstituent and the $\beta$-phase after $6 \mathrm{~h}$ of immersion in the electrolyte. Next, it propagated within the eutectic microconstituent and the magnesium matrix. The $\beta$-phase remained unaffected by the corrosion process up to $40 \mathrm{~h}$ of immersion. After $72 \mathrm{~h}$, the microstructure was severely 

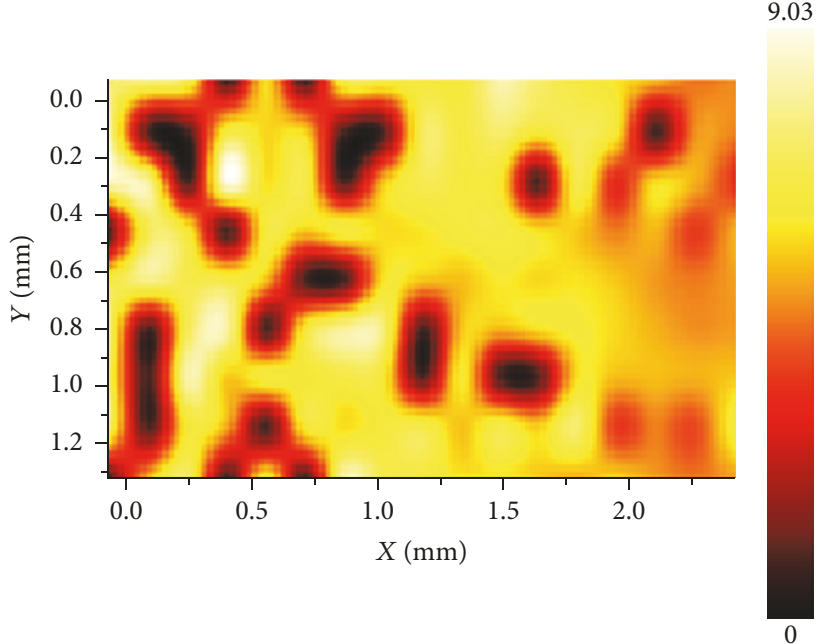

(a)

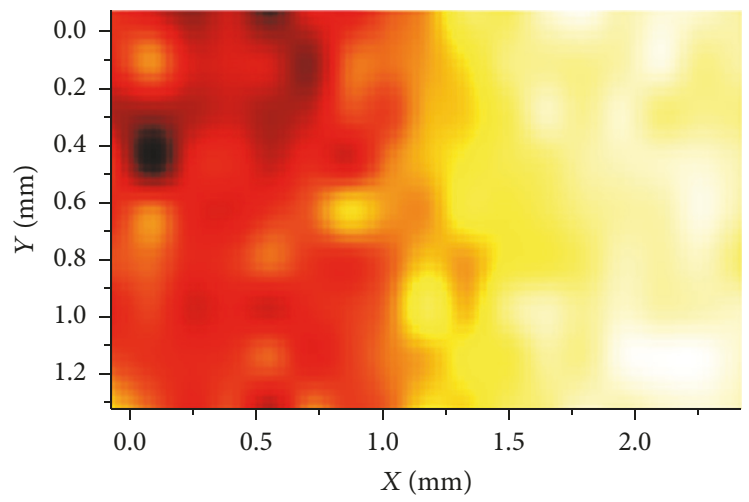

(b)

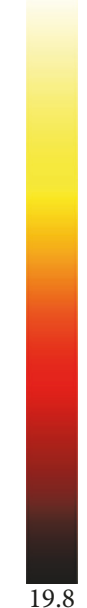

74.0
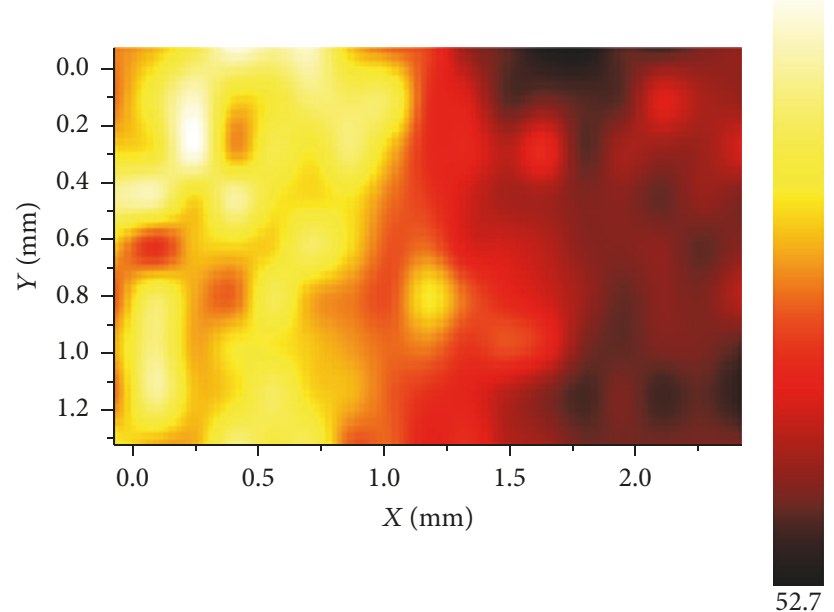

(c)

FIGURE 12: XPS maps for the atomic percentages of (a) Al2p; (b) O1s; and (c) Mg1s for the as-received AZ91D alloy. 


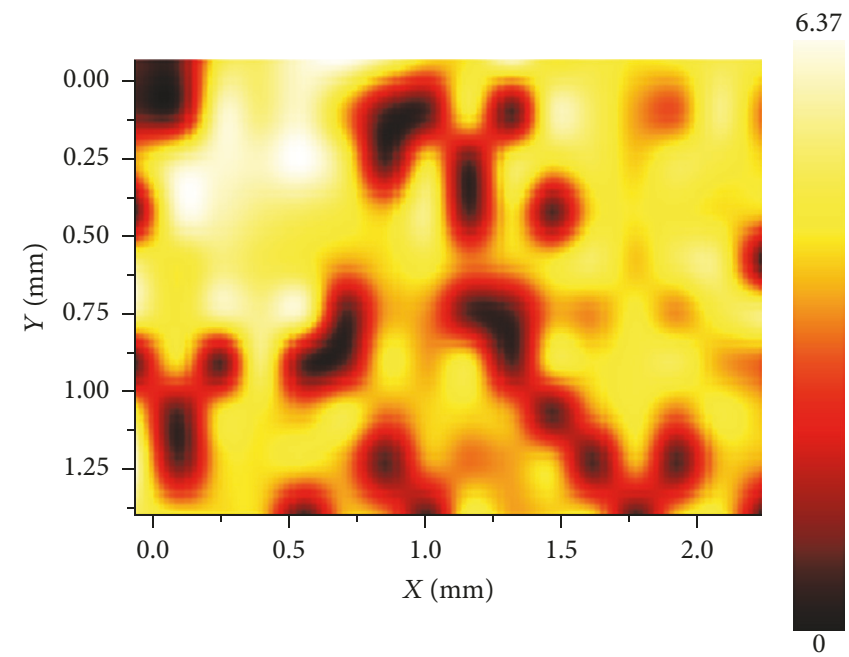

(a)

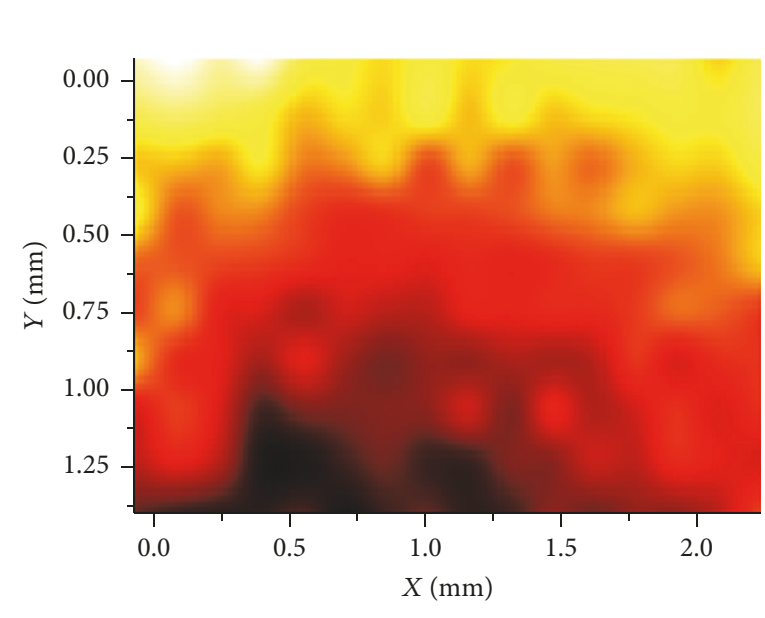

56.7

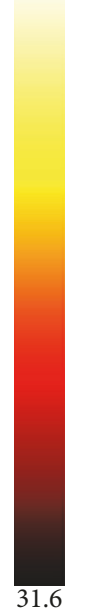

(b)

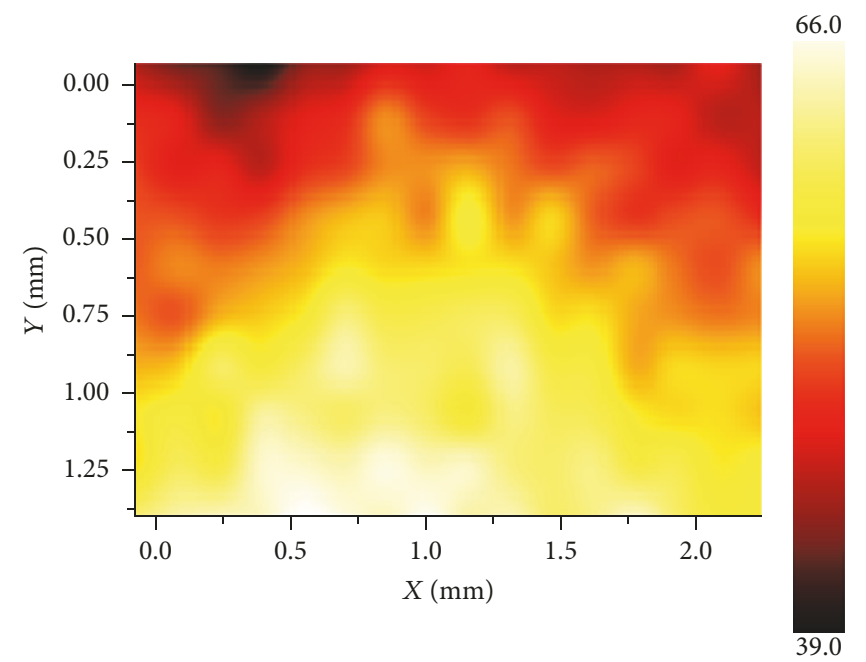

(c)

FIGURE 13: XPS maps for the atomic percentages of (a) Al2p; (b) O1s; and (c) Mg1s for the AZ91D alloy immersed for 1 minute in 3.5 wt.\% $\mathrm{NaCl}$ solution at room temperature. 


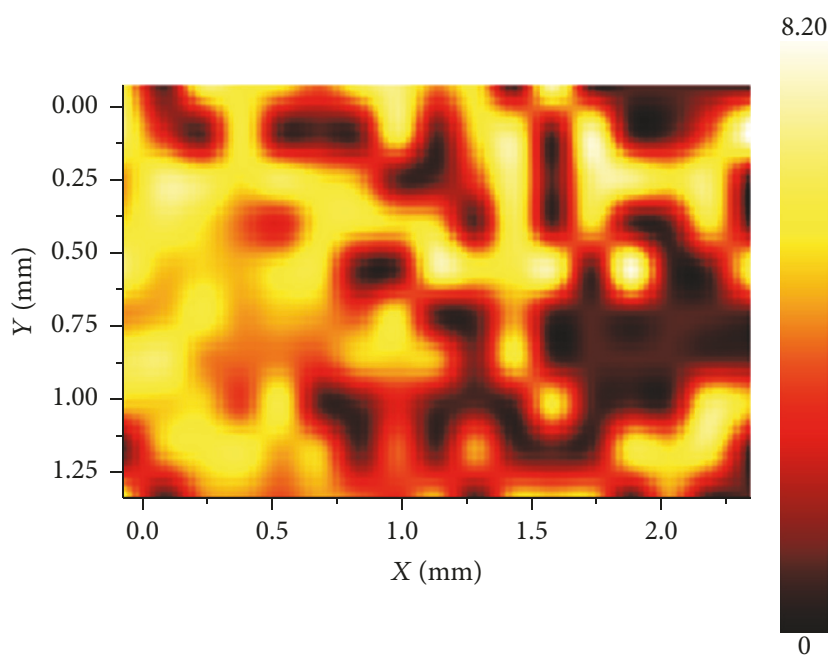

(a)

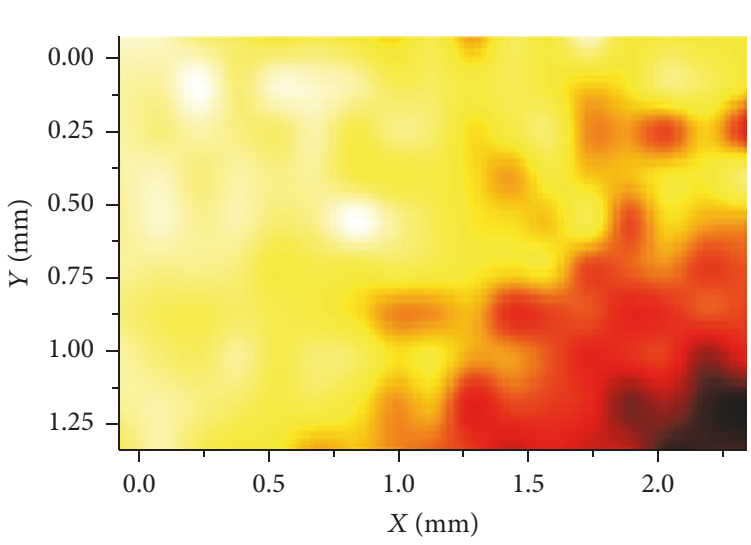

(b)

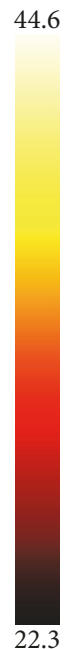

$$
76.3
$$

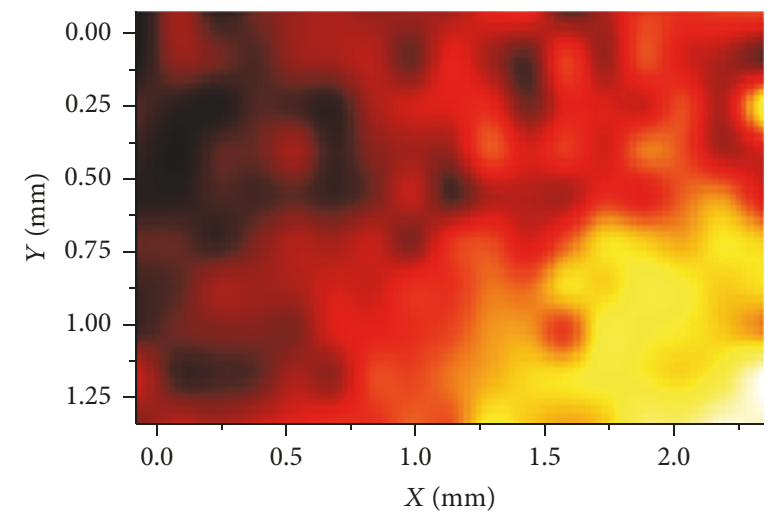

(c)

FIGURE 14: XPS maps for the atomic percentages of (a) Al2p; (b) O1s; and (c) Mg1s for the AZ91D alloy immersed for 30 minutes in 3.5 wt.\% $\mathrm{NaCl}$ solution at room temperature. 


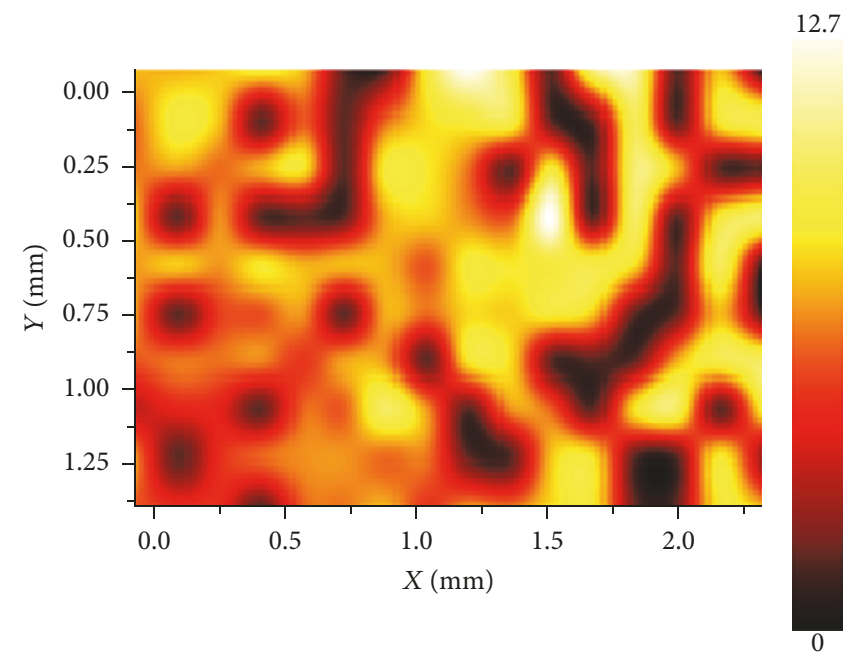

(a)

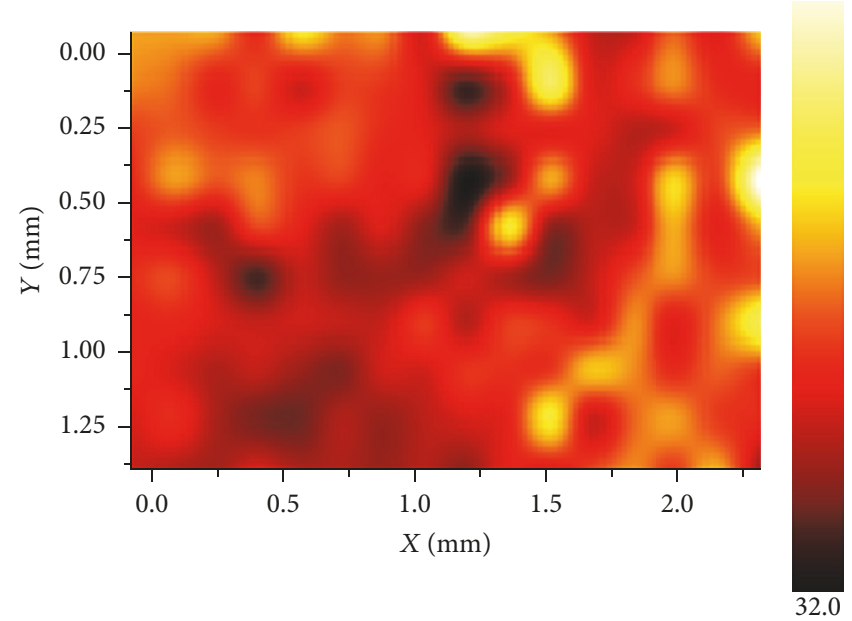

(b)

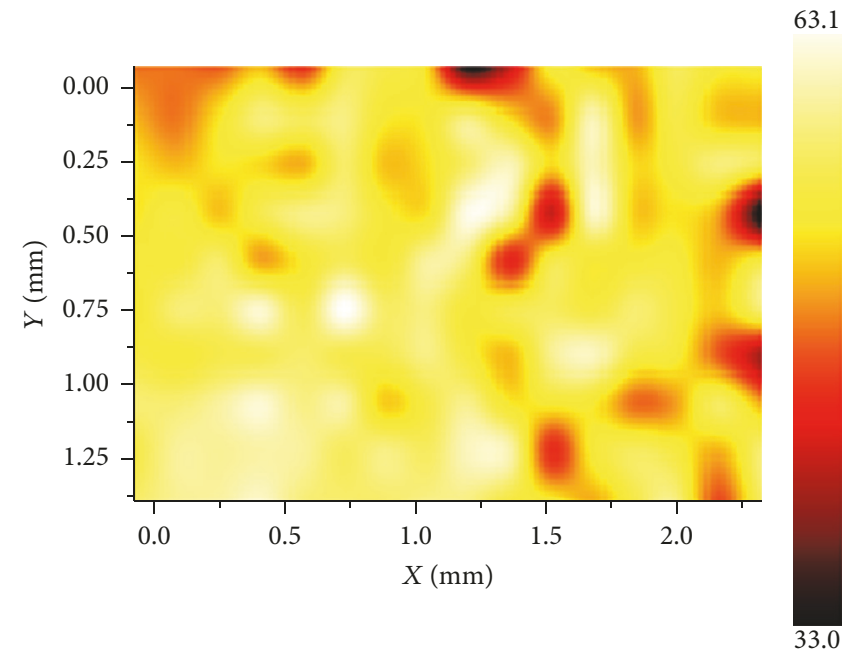

(c)

FIGURE 15: XPS maps for the atomic percentages of (a) Al2p; (b) O1s; and (c) Mg1s for the AZ91D alloy immersed for $3 \mathrm{~h}$ in $3.5 \mathrm{wt} . \% \mathrm{NaCl}$ solution at room temperature. 


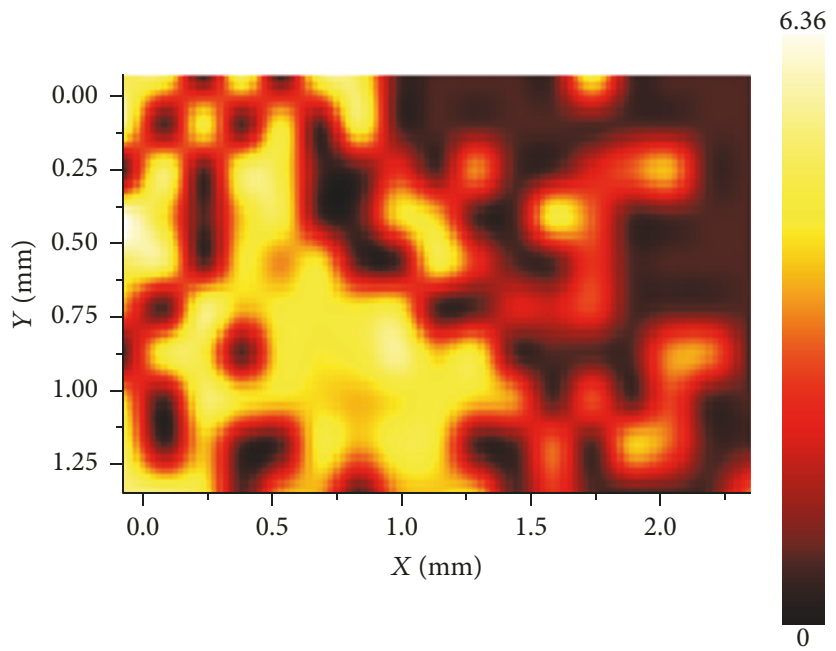

(a)

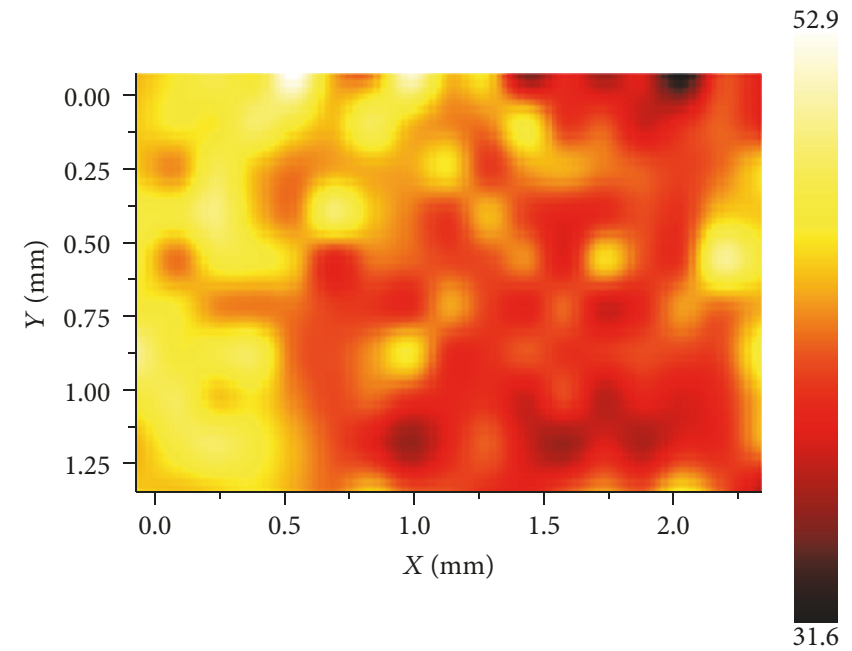

(b)

67.8

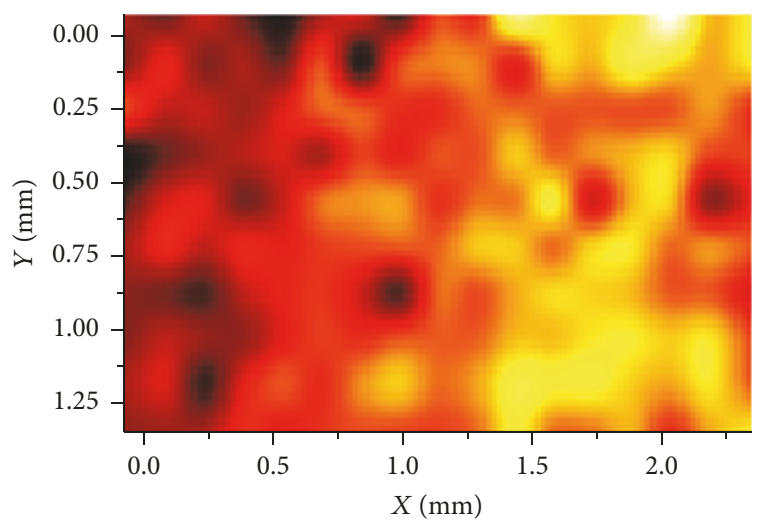

(c)

FIGURE 16: XPS maps for the atomic percentages of (a) Al2p; (b) O1s; and (c) Mg1s for the AZ91D alloy immersed for $6 \mathrm{~h}$ in $3.5 \mathrm{wt} . \% \mathrm{NaCl}$ solution at room temperature. 


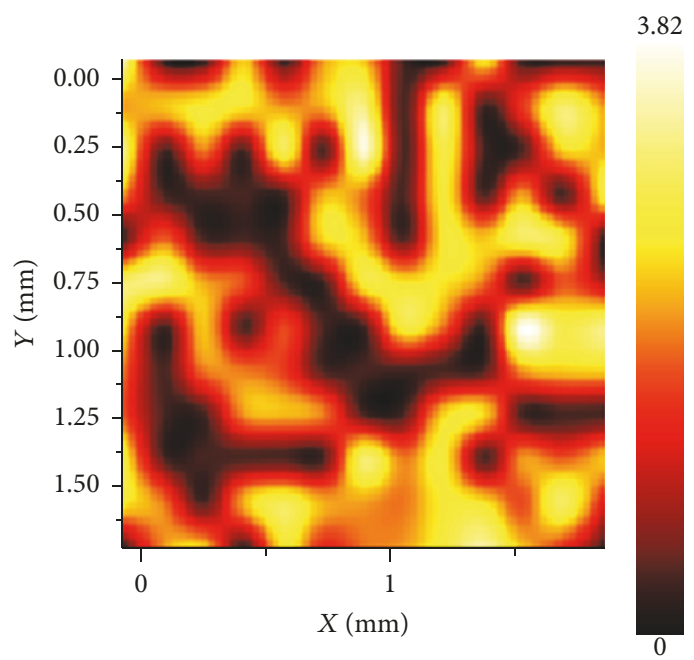

(a)

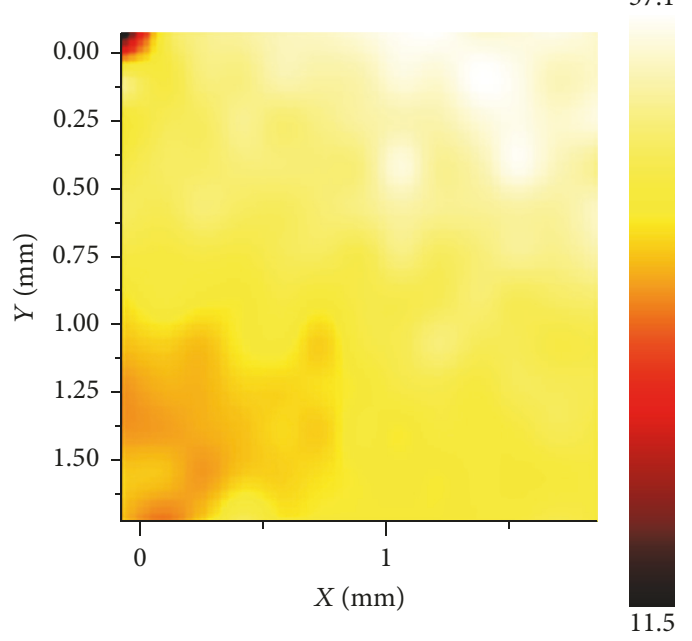

(b)

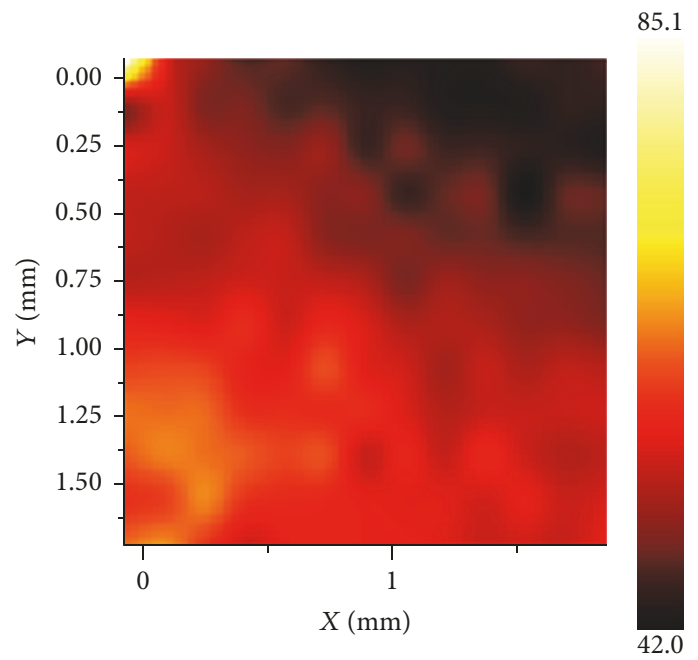

(c)

FIGURE 17: XPS maps for the atomic percentages of (a) Al2p; (b) O1s; and (c) Mg1s for the AZ91D alloy immersed for $15 \mathrm{~h}$ in $3.5 \mathrm{wt} . \% \mathrm{NaCl}$ solution at room temperature. 


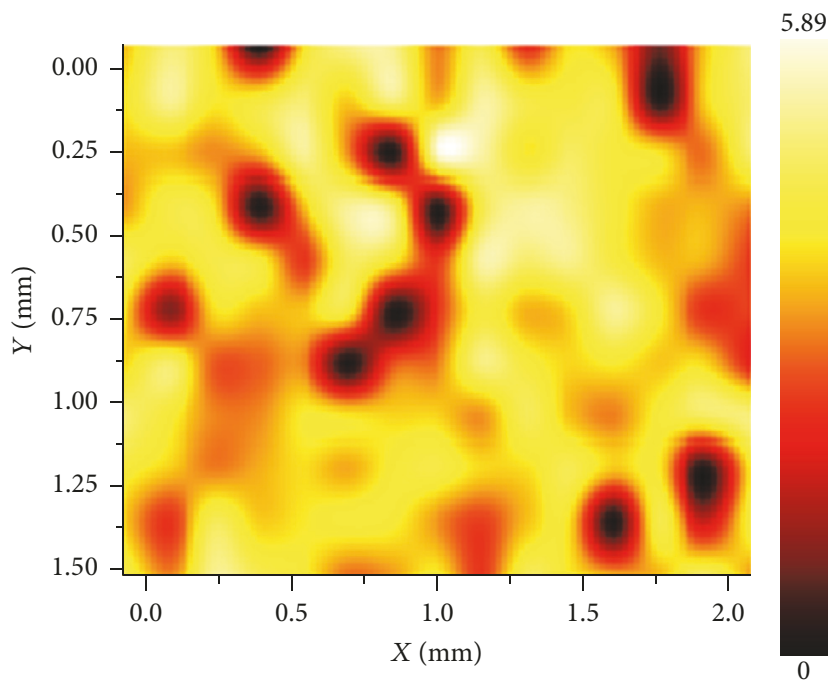

(a)

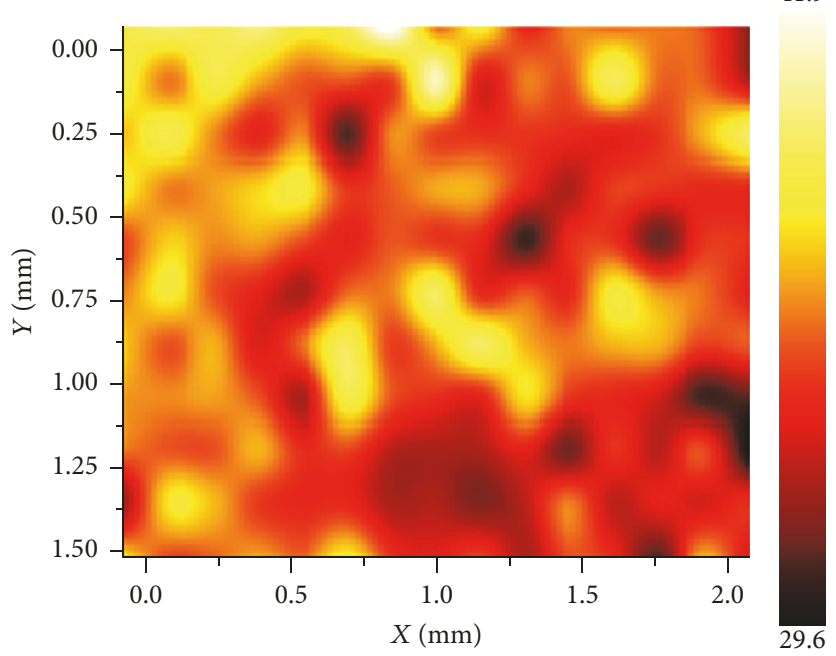

(b)

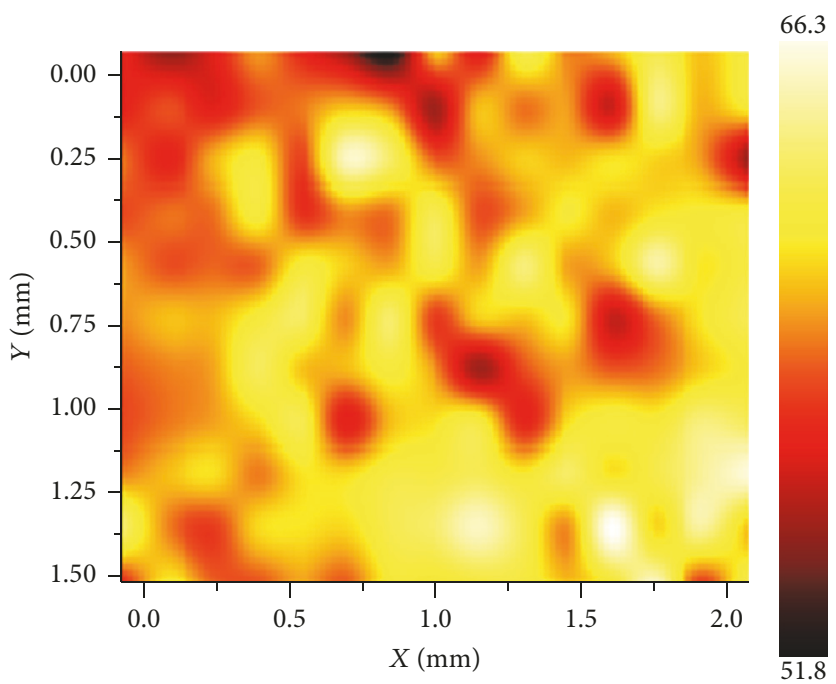

(c)

FIGURE 18: XPS maps for the atomic percentages of (a) Al2p; (b) O1s; and (c) Mgls for the AZ91D alloy immersed for $40 \mathrm{~h}$ in $3.5 \mathrm{wt} . \% \mathrm{NaCl}$ solution at room temperature. 


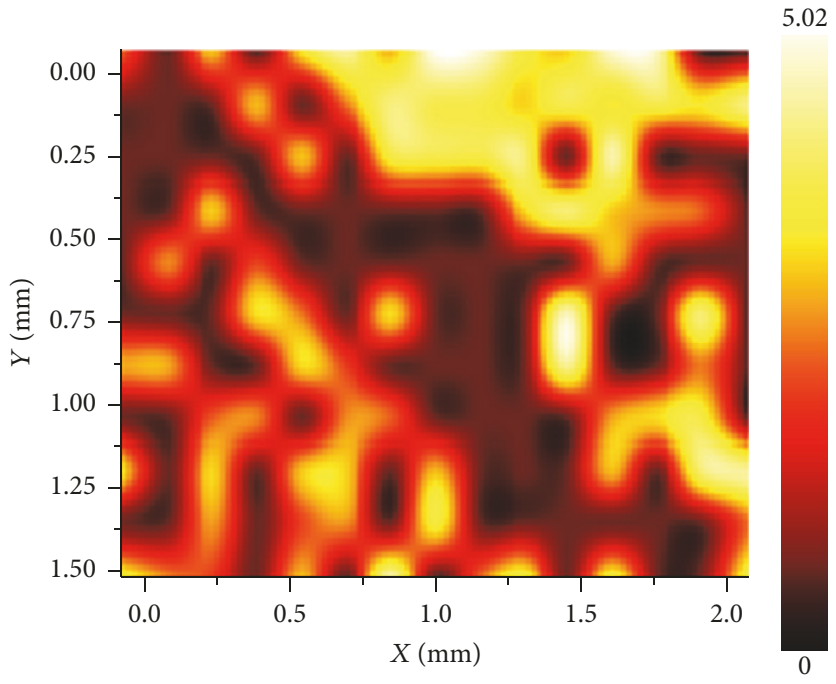

(a)

46.5

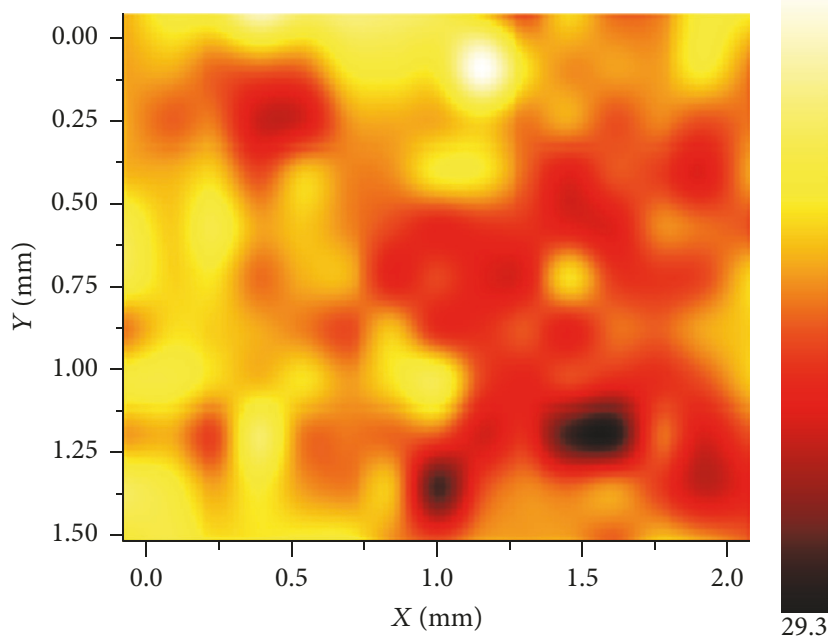

(b)

68.5

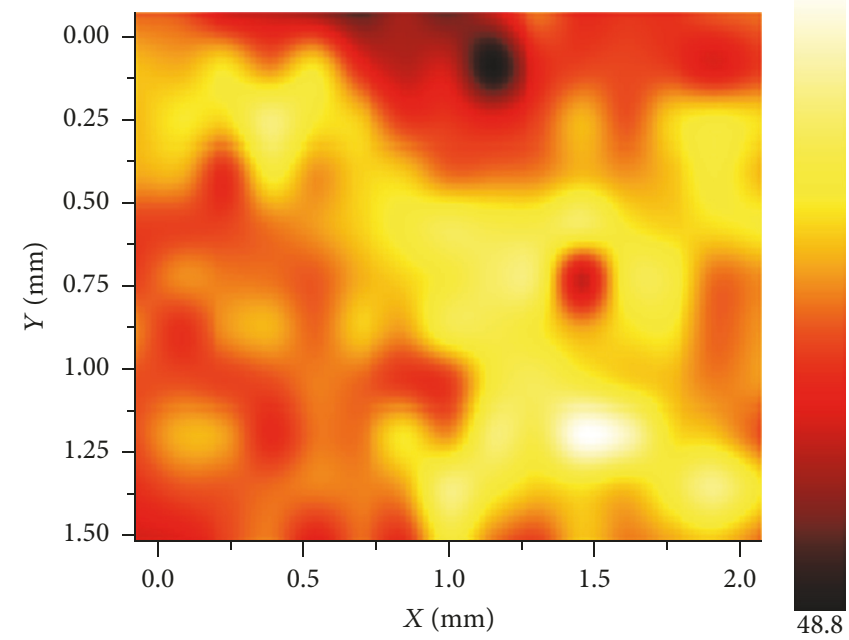

(c)

FIGURE 19: XPS maps for the atomic percentages of (a) Al2p; (b) O1s; and (c) Mg1s for the AZ91D alloy immersed for $72 \mathrm{~h}$ in $3.5 \mathrm{wt} . \% \mathrm{NaCl}$ solution at room temperature. 
corroded, even at the $\beta$-phase. Corrosion was found to preferentially begin at the regions where the $\beta$-phase was discontinuously distributed within the magnesium matrix. XPS mapping revealed that the oxygen atomic concentration was dependent on the immersion time and the composition of the oxide layer was related to the electrochemical behavior observed by EIS.

\section{Data Availability}

Data will be made available upon request.

\section{Conflicts of Interest}

The authors declare that they have no conflicts of interest.

\section{Acknowledgments}

Rima Industrial Magnésio (Brazil) is kindly acknowledged for providing the AZ91D ingot studied in this work. The authors are also thankful to Dr. Nelson Batista de Lima (IPEN/CNEN-SP) for the X-ray diffraction analysis.

\section{References}

[1] Y. Tian, L.-J. Yang, Y.-F. Li et al., "Corrosion behaviour of diecast AZ91D magnesium alloys in sodium sulphate solutions with different $\mathrm{pH}$ values," Transactions of Nonferrous Metals Society of China, vol. 21, no. 4, pp. 912-920, 2011.

[2] T. Li, H. Zhang, Y. He, and X. Wang, "Comparison of corrosion behavior of $\mathrm{Mg}-1.5 \mathrm{Zn}-0.6 \mathrm{Zr}$ and AZ91D alloys in a $\mathrm{NaCl}$ solution," Materials and Corrosion, vol. 66, no. 1, pp. 7-15, 2015.

[3] M. Laleh and F. Kargar, "Effect of surface nanocrystallization on the microstructural and corrosion characteristics of AZ91D magnesium alloy," Journal of Alloys and Compounds, vol. 509, no. 37, pp. 9150-9156, 2011.

[4] A. A. Luo, "Magnesium casting technology for structural applications," Journal of Magnesium and Alloys, vol. 1, no. 1, pp. 2-22, 2013.

[5] M. Ö. Öteyaka, E. Ghali, and R. Tremblay, "Corrosion behaviour of AZ and ZA magnesium alloys in alkaline chloride media," International Journal of Corrosion, vol. 2012, Article ID 452631, 10 pages, 2012.

[6] D. Y. Hwang, Y. M. Kim, D.-Y. Park, B. Yoo, and D. H. Shin, "Corrosion resistance of oxide layers formed on AZ91 Mg alloy in $\mathrm{KMnO}_{4}$ electrolyte by plasma electrolytic oxidation," Electrochimica Acta, vol. 54, no. 23, pp. 5479-5485, 2009.

[7] M. C. L. De Oliveira, V. S. M. Pereira, O. V. Correa, and R. A. Antunes, "Corrosion performance of anodized AZ91D magnesium alloy: effect of the anodizing potential on the film structure and corrosion behavior," Journal of Materials Engineering and Performance, vol. 23, no. 2, pp. 593-603, 2014.

[8] L. Zhang, Q. Wang, W. Liao et al., "Effect of homogenization on the microstructure and mechanical properties of the repetitiveupsetting processed AZ91D alloy," Journal of Materials Science and Technology, vol. 33, no. 9, pp. 935-940, 2017.

[9] Z. Li, A. A. Luo, Q. Wang, H. Zou, J. Dai, and L. Peng, "Fatigue characteristics of sand-cast AZ91D magnesium alloy," Journal of Magnesium and Alloys, vol. 5, no. 1, pp. 1-12, 2017.
[10] G. Ballerini, U. Bardi, R. Bignucolo, and G. Ceraolo, "About some corrosion mechanisms of AZ91D magnesium alloy," Corrosion Science, vol. 47, no. 9, pp. 2173-2184, 2005.

[11] M. C. L. de Oliveira, V. S. M. Pereira, O. V. Correa, N. B. de Lima, and R. A. Antunes, "Correlation between the corrosion resistance and the semiconducting properties of the oxide film formed on AZ91D alloy after solution treatment," Corrosion Science, vol. 69, pp. 311-321, 2013.

[12] W. Zhou, T. Shen, and N. N. Aung, "Effect of heat treatment on corrosion behaviour of magnesium alloy AZ91D in simulated body fluid," Corrosion Science, vol. 52, no. 3, pp. 1035-1041, 2010.

[13] D. Zander and C. Schnatterer, "The influence of manufacturing processes on the microstructure and corrosion of the AZ91D magnesium alloy evaluated using a computational image analysis," Corrosion Science, vol. 98, pp. 291-303, 2015.

[14] G. Song, A. Atrens, X. Wu, and B. Zhang, "Corrosion behaviour of AZ21, AZ501 and AZ91 in sodium chloride," Corrosion Science, vol. 40, no. 10, pp. 1769-1791, 1998.

[15] G. Song, A. Atrens, and M. Dargusch, "Influence of microstructure on the corrosion of diecast AZ91D," Corrosion Science, vol. 41, no. 2, pp. 249-273, 1998.

[16] R. Ambat, N. N. Aung, and W. Zhou, "Evaluation of microstructural effects on corrosion behaviour of AZ91D magnesium alloy," Corrosion Science, vol. 42, no. 8, pp. 1433-1455, 2000.

[17] M. Jönsson and D. Persson, "The influence of the microstructure on the atmospheric corrosion behaviour of magnesium alloys AZ91D and AM50," Corrosion Science, vol. 52, no. 3, pp. 1077-1085, 2010.

[18] O. Lunder, J. E. Lein, T. K. Aune, and K. Nisancioglu, "Role of Mg17Al12 phase in the corrosion of Mg alloy AZ91," Corrosion, vol. 45, no. 9, pp. 741-748, 1989.

[19] M. Gobara, M. Shamekh, and R. Akid, "Improving the corrosion resistance of AZ91D magnesium alloy through reinforcement with titanium carbides and borides," Journal of Magnesium and Alloys, vol. 3, no. 2, pp. 112-120, 2015.

[20] M. Esmaily, J. E. Svensson, S. Fajardo et al., "Fundamentals and advances in magnesium alloy corrosion," Progress in Materials Science, vol. 89, pp. 92-193, 2017.

[21] I. B. Singh, M. Singh, and S. Das, "A comparative corrosion behavior of $\mathrm{Mg}$, AZ31 and AZ91 alloys in 3.5\% $\mathrm{NaCl}$ solution," Journal of Magnesium and Alloys, vol. 3, no. 2, pp. 142-148, 2015.

[22] M. Esmaily, D. B. Blücher, J. E. Svensson, M. Halvarsson, and L. G. Johansson, "New insights into the corrosion of magnesium alloys-the role of aluminum," Scripta Materialia, vol. 115, pp. 91-95, 2016.

[23] R. Leiva-García, J. García-Antón, and M. J. Muñoz-Portero, Application of Confocal Laser Scanning Microscopy to the In-situ and Ex-situ Study of Corrosion Processes, Laser Scanning, Theory and Applications, C. C. Wang, Ed., InTech, 2011.

[24] M. Jönsson, D. Persson, and R. Gubner, "The initial steps of atmospheric corrosion on magnesium alloy AZ91D," Journal of The Electrochemical Society, vol. 154, no. 11, pp. C684-C691, 2007.

[25] O. Schneider, G. O. Ilevbare, J. R. Scully, and R. G. Kelly, "Confocal laser scanning microscopy as a tool for in situ monitoring of corrosion underneath organic coatings," Electrochemical and Solid-State Letters, vol. 4, no. 12, pp. B35-B38, 2001.

[26] P. Jakupi, J. J. Noël, and D. W. Shoesmith, "The evolution of crevice corrosion damage on the Ni-Cr-Mo-W alloy-22 determined by confocal laser scanning microscopy," Corrosion Science, vol. 54, no. 1, pp. 260-269, 2012. 
[27] M. P. Garcia, G. L. Mantovani, R. Vasant Kumar, and R. A. Antunes, "Corrosion behavior of metal active gas welded joints of a high-strength steel for automotive application," Journal of Materials Engineering and Performance, vol. 26, no. 10, pp. 47184731, 2017.

[28] R. M. Fernández-Domene, E. Blasco-Tamarit, D. M. GarcíaGarcía, and J. García-Antón, "Repassivation of the damage generated by cavitation on UNS N08031 in a LiBr solution by means of electrochemical techniques and Confocal Laser Scanning Microscopy," Corrosion Science, vol. 52, no. 10, pp. 3453-3464, 2010.

[29] R. Leiva-García, J. García-Antón, and M. J. Muñoz-Portero, "Contribution to the elucidation of corrosion initiation through confocal laser scanning microscopy (CLSM)," Corrosion Science, vol. 52, no. 6, pp. 2133-2142, 2010.

[30] C. Y. Cui, X. G. Cui, Y. K. Zhang et al., "Microstructure and corrosion behavior of the AISI 304 stainless steel after Nd:YAG pulsed laser surface melting," Surface and Coatings Technology, vol. 206, no. 6, pp. 1146-1154, 2011.

[31] A. H. Feng and Z. Y. Ma, "Enhanced mechanical properties of $\mathrm{Mg}-\mathrm{Al}-\mathrm{Zn}$ cast alloy via friction stir processing," Scripta Materialia, vol. 56, no. 5, pp. 397-400, 2007.

[32] Y. Fan, G. Wu, H. Gao, and C. Zhai, "Influence of Ca on corrosion resistance of AZ91D," Journal of The Electrochemical Society, vol. 153, no. 8, Article ID 002608JES, pp. B283-B288, 2006.

[33] M. Sumida, S. Jung, and T. Okane, "Solidification microstructure, thermal properties and hardness of magnesium alloy 20 mass \% Gd added AZ91D," Materials Transactions, vol. 50, no. 5, pp. 1161-1168, 2009.

[34] Y. C. Guan, W. Zhou, and H. Y. Zheng, "Effect of laser surface melting on corrosion behaviour of AZ91D Mg alloy in simulated-modified body fluid," Journal of Applied Electrochemistry, vol. 39, no. 9, pp. 1457-1464, 2009.

[35] A. S. Hamdy, E. El-Shenaw, and T. El-Bitar, "Electrochemical impedance spectroscopy study of the corrosion behavior of some niobium bearing stainless steels in 3.5\% NaCl," International Journal of Electrochemical Science, vol. 1, no. 4, pp. 171-180, 2006.

[36] E.-S. M. Sherif, "A comparative study on the electrochemical corrosion behavior of iron and X-65 steel in $4.0 \mathrm{wt} \%$ sodium chloride solution after different exposure intervals," Molecules, vol. 19, no. 7, pp. 9962-9974, 2014.

[37] F. Farelas and A. Ramirez, "Carbon dioxide corrosion inhibition of carbon steels through bis-imidazoline and imidazoline compounds studied by EIS," International Journal of Electrochemical Science, vol. 5, no. 6, pp. 797-814, 2010. 


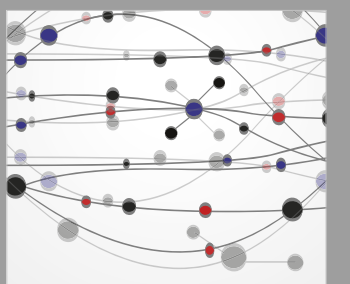

The Scientific World Journal
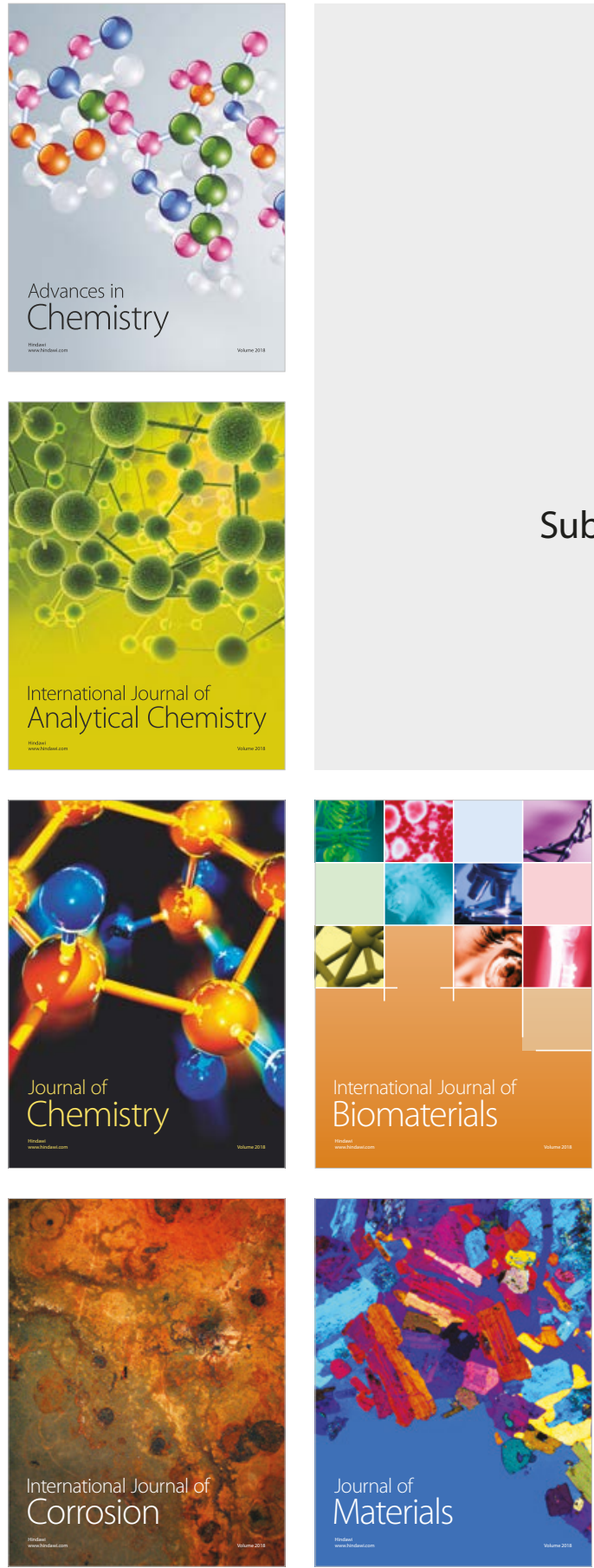

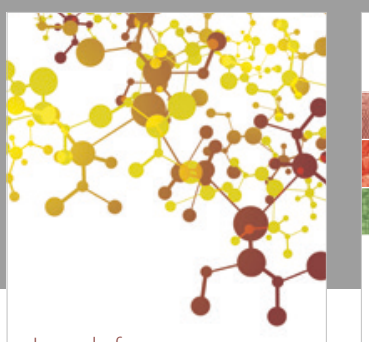

Journal of

Applied Chemistry
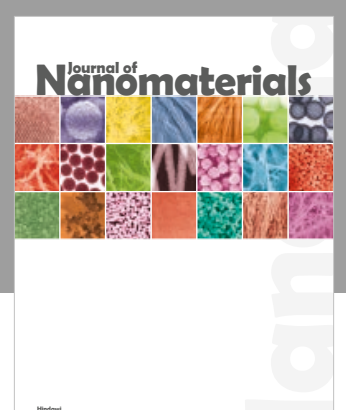

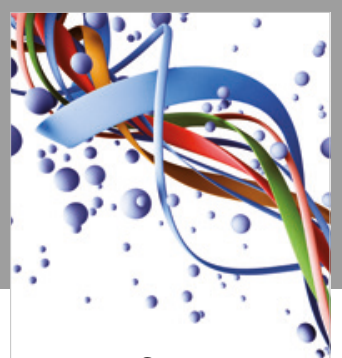

Scientifica

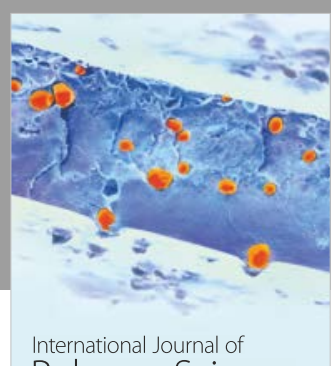

Polymer Science

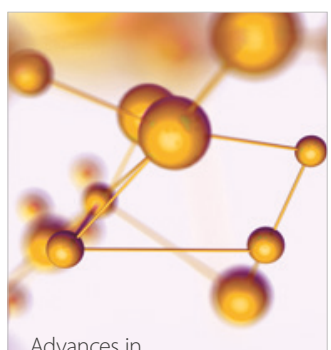

Physical Chemistry
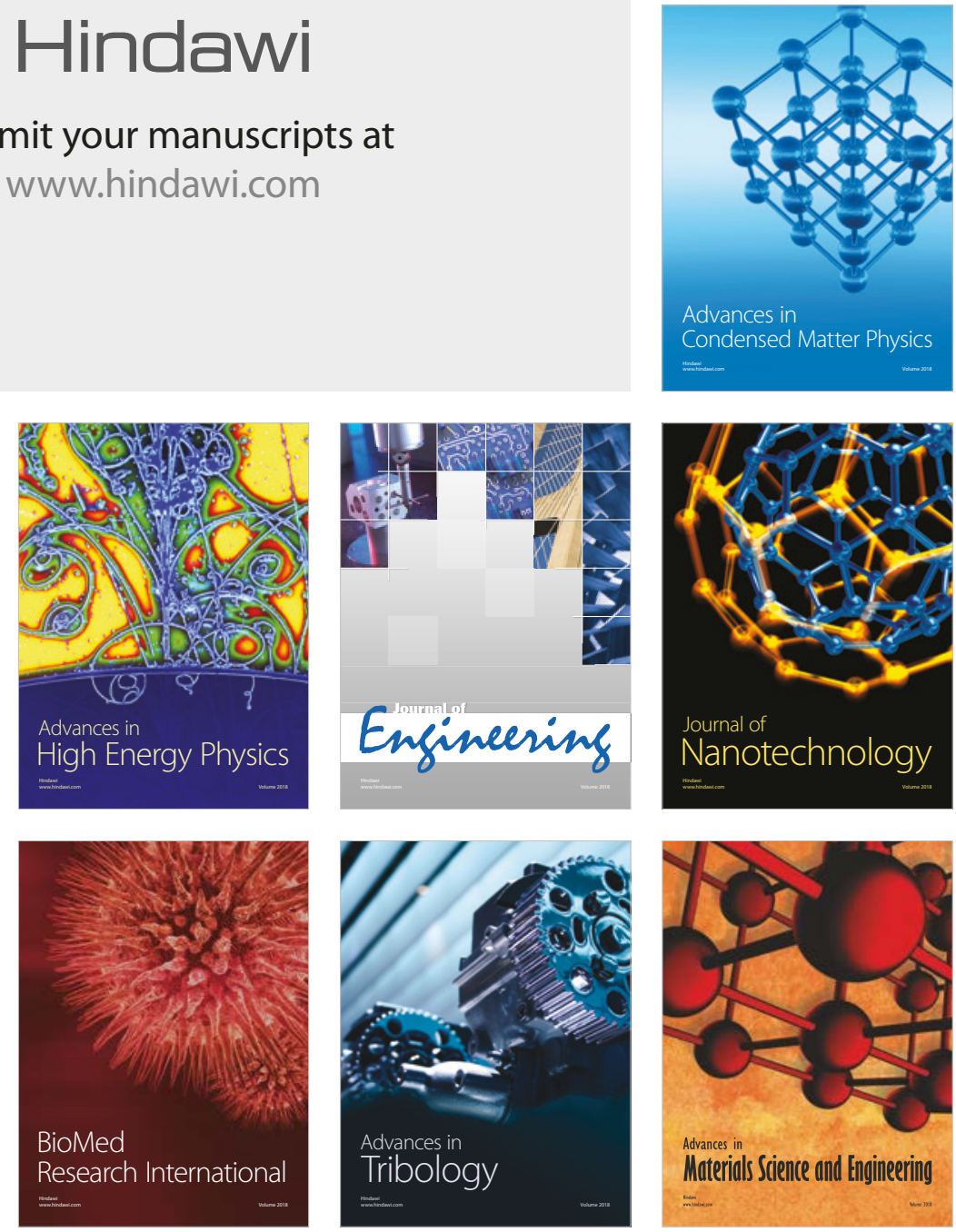